\title{
L-Arginine/Nitric Oxide Pathway Is Altered in Colorectal Cancer and Can Be Modulated by Novel Derivatives from Oxicam Class of Non-Steroidal Anti-Inflammatory Drugs
}

\author{
Małgorzata Krzystek-Korpacka 1,*D, Berenika Szczęśniak-Sięga ${ }^{2}$, Izabela Szczuka ${ }^{1}$, \\ Paulina Fortuna ${ }^{1}$ D, Marek Zawadzki ${ }^{3,4}$, Agnieszka Kubiak ${ }^{1}$, Magdalena Mierzchała-Pasierb ${ }^{1}$, \\ Mariusz G. Fleszar ${ }^{1}$ (D) , tukasz Lewandowski ${ }^{1}$ (D), Paweł Serek ${ }^{1}$, Natalia Jamrozik ${ }^{1}$ (D), \\ Katarzyna Neubauer ${ }^{5}$, Jerzy Wiśniewski ${ }^{1}$ D , Radosław Kempiński ${ }^{5}$, Wojciech Witkiewicz ${ }^{3,6}$ \\ and Iwona Bednarz-Misa ${ }^{1}$ (D) \\ 1 Department of Medical Biochemistry, Wroclaw Medical University, 50-368 Wroclaw, Poland; \\ izabela.szczuka@umed.wroc.pl (I.S.); paulina.fortuna@umed.wroc.pl (P.F.); a.kubiak@umed.wroc.pl (A.K.); \\ magdalena.mierzchala-pasierb@umed.wroc.pl (M.M.-P.); fleszar.mariusz@gmail.com (M.G.F.); \\ lukasz.lewandowski@umed.wroc.pl (Ł.L.); pawel.serek@umed.wroc.pl (P.S.); \\ natalia.jamrozik@student.umed.wroc.pl (N.J.); jerzy.wisniewski@umed.wroc.pl (J.W.); \\ iwona.bednarz-misa@umed.wroc.pl (I.B.-M.) \\ 2 Department of Medicinal Chemistry, Faculty of Pharmacy, Wroclaw Medical University, \\ 50-556 Wroclaw, Poland; berenika.szczesniak-siega@umed.wroc.pl \\ 3 Department of Oncological Surgery, Regional Specialist Hospital, 51-124 Wroclaw, Poland; \\ zawadzki@wssk.wroc.pl (M.Z.); witkiewicz@wssk.wroc.pl (W.W.) \\ 4 Department of Physiotherapy, Wroclaw Medical University, 51-618 Wroclaw, Poland \\ 5 Department of Gastroenterology and Hepatology, Wroclaw Medical University, 50-556 Wroclaw, Poland; \\ katarzyna.neubauer@umed.wroc.pl (K.N.); radoslaw.kempinski@umed.wroc.pl (R.K.) \\ 6 Research and Development Centre at Regional Specialist Hospital, 51-124 Wroclaw, Poland \\ * Correspondence: malgorzata.krzystek-korpacka@umed.wroc.pl; Tel.: +48-71-784-1375
}

Received: 31 July 2020; Accepted: 10 September 2020; Published: 11 September 2020

check for updates

Simple Summary: Nitric oxide and arginine metabolism in colorectal cancer (CRC) holds potential for therapeutic intervention. We hypothesized that it can be modulated by oxicams, a class of non-steroidal anti-inflammatory drugs with documented chemopreventive and antineoplastic activity. The aim of this study was to determine the transcriptional patterns of pathway enzymes in CRC and evaluate the impact of classic and new oxicam analogues. Arginine metabolic pathways were altered not only in tumors but also in non-transformed mucosa from tumor vicinity, contributing to the phenomenon of tumor molecular margin. Classic oxicams, piroxicam and meloxicam, had negligible impact but their new analogues downregulated expression of dimethylarginine dimethylaminohydrolases and protein methyltransferases and upregulated asymmetric dimethylarginine. Those beneficial effects were accompanied by upregulation of arginase- 2 and the potentially disadvantageous accumulation of arginine and symmetric dimethylarginine. Our findings provide novel insight into metabolic reprogramming in CRC and demonstrate that oxicam analogues are worth further consideration as novel anticancer agents.

Abstract: L-arginine/nitric oxide pathway metabolites are altered in colorectal cancer (CRC). We evaluated underlying changes in pathway enzymes in 55 paired tumor/tumor-adjacent samples and 20 normal mucosa using quantitative-PCR and assessed the impact of classic and novel oxicam analogues on enzyme expression and intracellular metabolite concentration (LC-MS/MS) in Caco-2, HCT116, and HT-29 cells. Compared to normal mucosa, ARG1, PRMT1, and PRMT5 were overexpressed in both tumor and tumor-adjacent tissue and DDAH2 solely in tumor-adjacent 
tissue. Tumor-adjacent tissue had higher expression of $A R G 1, D D A H 1$, and DDAH2 and lower NOS2 than patients-matched tumors. The $A R G 1$ expression in tumors increased along with tumor grade and reflected lymph node involvement. Novel oxicam analogues with arylpiperazine moiety at the thiazine ring were more effective in downregulating DDAHs and PRMTs and upregulating ARG2 than piroxicam and meloxicam. An analogue distinguished by propylene linker between thiazine's and piperazine's nitrogen atoms and containing two fluorine substituents was the strongest inhibitor of DDAHs and PRMTs expression, while an analogue containing propylene linker but no fluorine substituents was the strongest inhibitor of $A R G 2$ expression. Metabolic reprogramming in CRC includes overexpression of DDAHs and PRMTs in addition to ARG1 and NOS2 and is not restricted to tumor tissue but can be modulated by novel oxicam analogues.

Keywords: arginase (ARG); nitric oxide synthase (NOS); dimethylarginine dimethylaminohydrolase (DDAH); protein methyltransferases (PRMT); asymmetric dimethylarginine (ADMA); symmetric dimethylarginine (SDMA); dimethylamine (DMA); metabolic reprogramming; chemoprevention

\section{Introduction}

Colorectal cancer (CRC) remains one of the most common and lethal cancers, despite recent progress in the disease prevention and patients' management [1]. Latest advances in various "-omics", particularly genomics and proteomics, have improved our understanding of molecular landscape of CRC. Still, there are few resulting biomarkers to aid diagnosis and clinical-decision making or which serve as molecular targets for chemoprevention and treatment [2]. Metabolic reprogramming is one of eight recognized cancer hallmarks [3]. However, cancer metabolism is highly flexible and cancer typeand context-dependent [4]. Therefore, further research employing quantitative metabolic profiling is needed to translate metabolic abnormalities into clinical practice successfully [5].

We have recently demonstrated that CRC, as well as the disease-promoting conditions [6], is associated with systemic changes in metabolites of L-arginine/nitric oxide (NO) pathway, potentially applicable as CRC biomarkers and predictors of adverse clinical events after curative tumor resection [7]. In the present study, we aimed at transcriptional profiling of the underlying alterations in pathway enzymes as a follow-up. L-arginine (arginine) is a semi-essential amino acid, from which several biologically active substances are obtained. The main arginine-derived products are NO, co-synthesized with citrulline by a family of NO synthases (NOSs), and ornithine, co-synthesized with urea by arginases (ARGs) and subsequently used for polyamine synthesis. The NOS enzymes are inhibited, to varying degree, by asymmetric (ADMA) and symmetric (SDMA) dimethylarginines. Additionally, both metabolites compete with arginine for its membrane transporters. Dimethylamines are degradation products of proteins, methylated by protein methyltransferases (PRMTs). Type I enzymes (e.g., PRMT1) release ADMA and type II (e.g., PRMT5) release SDMA. The SDMA is removed by renal excretion while ADMA is degraded into dimethylamine (DMA) and citrulline by dimethylarginine dimethylaminohydrolases (DDAHs) [8,9]. An overview of L-arginine/NO pathway encompassing enzymes and metabolites determined in the present study is depicted in Figure 1. 


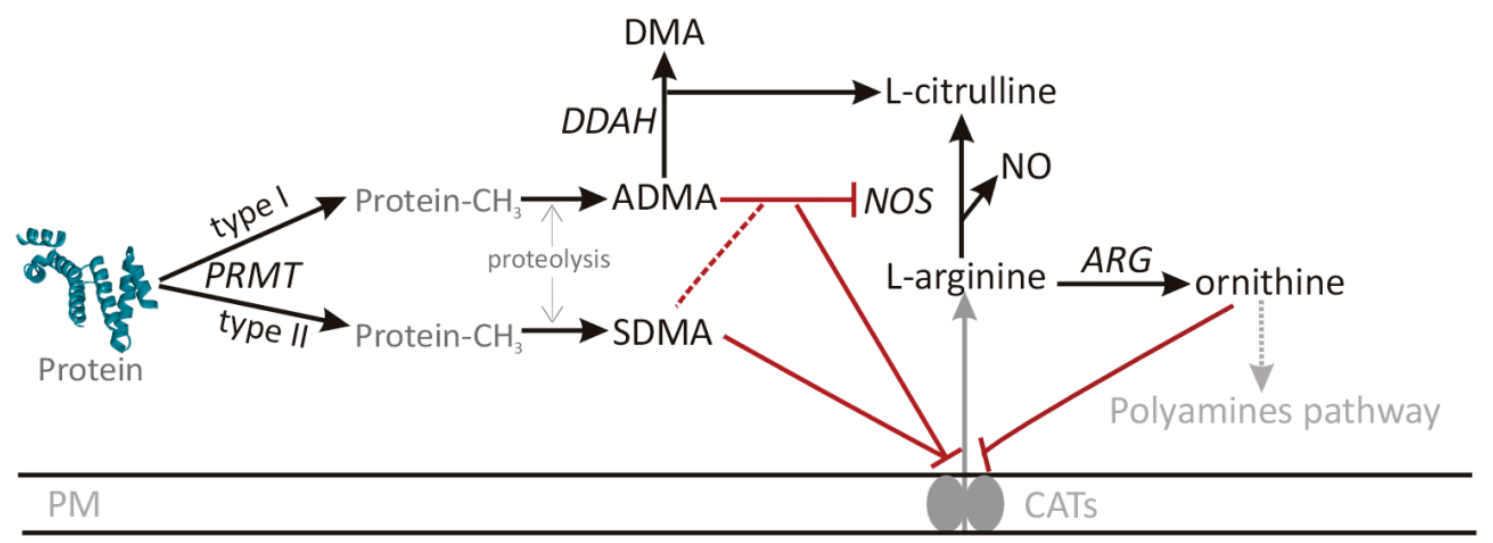

Figure 1. An overview of arginine/nitric oxide pathway. Metabolites are written in a straight script and enzymes in italics. Pathway components not determined in current study are marked in gray. Red color was used for inhibitory effects and a dashed line indicates weak impact. ADMA, asymmetric dimethylarginine; ARG, arginase; CATs, cationic amino acid transporter; DMA, dimethylamine; DDAH, dimethylarginine dimethylaminohydrolase; NOS, nitric oxide synthase; PM, plasma membrane; PRMT, protein methyltransferase.

The L-arginine pathway is potentially relevant for CRC development and progression [10-12]. However, arginine seems to play a dual role in carcinogenesis as its depletion hampers anticancer immunity [13]. Consequently, antineoplastic therapies based on arginine-deprivation or, on the contrary, the amino acid supplementation, are equally intensively investigated $[8,13,14]$. Moreover, there is also a growing interest in manipulating arginine metabolism as a chemoprevention, using specific inhibitors in combination with non-steroidal anti-inflammatory drugs (NSAIDs) [15-17]. While NSAIDs are proven anti-inflammatory agents, not all of their anticancer activity might be attributed to the downregulation of cyclooxygenases-mediated prostaglandin synthesis and the exact mechanisms involved in cancer chemoprevention remain elusive [18,19]. Recently, the chemopreventive activity of NSAIDs has been attributed, at least in part, to their interference with polyamine metabolism (reviewed in [19]). Here, we explored their potential effect on upstream L-arginine/NO pathway.

Oxicams are a class of NSAIDs, distinguished by the lack of a carboxyl group, which own their slightly acidic nature to an enolized $\beta$-dicarbonyl moiety. Structurally, they are benzothiazine-3-carboxylic acid amides (e.g., piroxicam, meloxicam) or thienothiazine-3-carboxylic acid amides [20]. Piroxicam and meloxicam have been shown to inhibit cancer cell growth [21-25] and angiogenesis [26] and to prevent surgery-induced emergence of secondary tumors [27], but their effect on the L-arginine/NO/ornithine pathway is largely unknown.

Therefore, this study was designed to determine metabolic reprogramming regarding L-arginine pathway enzymes in the colonic mucosa of CRC patients (ARG1, NOS2, DDAH1, DDAH2, PRMT1, and PRMT5) and to investigate the possible effect of selected oxicams on the pathway status in colorectal adenocarcinoma cell lines HCT 116, HT-29 and Caco-2, at the level of both metabolome (arginine, citrulline, ornithine, ADMA, SDMA, DMA, nitrates, and nitrites) and transcriptome (ARG2, NOS2, $D D A H 1, D D A H 2, P R M T 1$, and PRMT5). In addition to classic drugs-meloxicam and piroxicam-five recently synthesized [28] oxicam analogues have been evaluated. Novel drugs, denoted as compounds \#1-5 (Figure S1), possess a 1,2-benzothiazine oxicams scaffold and modified substituents in the 2-and 3-positions of the thiazine ring (Figure 2). 


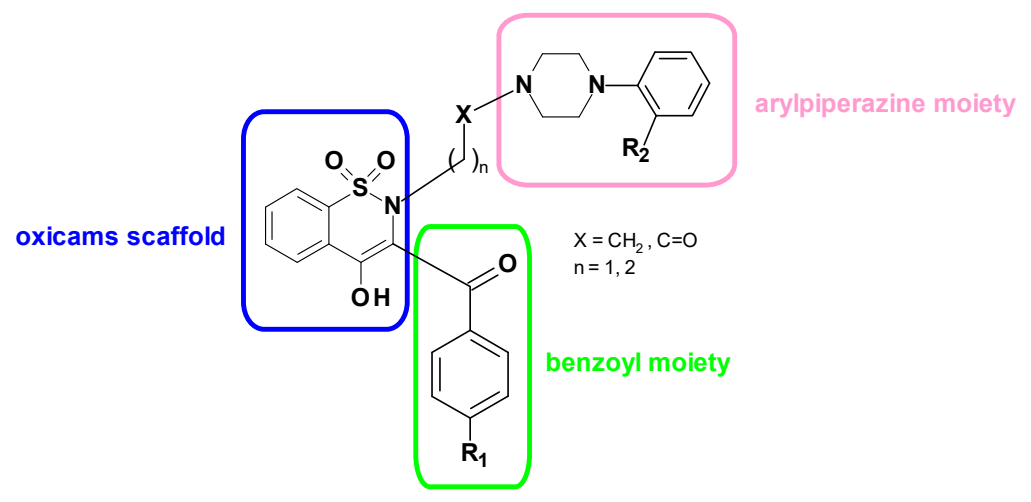

Figure 2. General structure of new oxicam analogues.

\section{Results}

\subsection{Arginine/No Pathway Enzymes in CRC Patients}

A transcriptional analysis of 55 pairs of patients'-matched colorectal samples-tumor and macroscopically normal mucosa adjacent to tumor-was conducted. Using reversely-transcribed quantitative (real-time) PCR and EvaGreen chemistry, the relative expression of $A R G 1, D D A H 1$, DDAH2, NOS2, PRMT1, and PRMT5, encoding key pathway enzymes, was determined.

\subsubsection{Pathway Enzymes in Patient-Matched Tumors and Non-Cancerous Tumor-Adjacent Tissue}

Pairwise analysis showed significantly downregulated expression of $A R G 1$ (by 2.2-fold, $p=0.025$ ), $D D A H 1$ (by 1.4-fold, $p=0.016$ ), and DDAH2 (by 1.6-fold, $p=0.005$ ) and upregulated expression of NOS2 (by 2.6-fold, $p=0.003$ ) in tumor as compared to adjacent, macroscopically normal tissue. The expression of PRMT5 tended to be upregulated as well (by 1.2-fold, $p=0.081$ ) while that of PRMT1 showed no difference $(p=0.850)$ (Figure S2).

\subsubsection{Association of Enzyme Expression Level with Cancer Pathology}

Fold-change in expression (tumor-to-adjacent) was calculated and referred to cancer pathology. Fold-change in ARG1 increased along with tumor grade ( $\rho=0.36, p=0.031)$ and growing $\mathrm{N}$ stage (N0-N1-N2): $\rho=0.35, p=0.031$. It was higher in patients with lymph node involvement (N1 and N2) than without (N0) by 7.1-fold ( $p=0.017$ ) and in stage III/IV than $0 / \mathrm{I} / \mathrm{II}$ by 7.9 -fold $(p=0.014)$. The DDAH2 expression tended to be less decreased in N1/N2 than N0 cancers (by 1.5-fold, $p=0.059$ ) and stage III/IV than 0/I/II cancers (by 1.5-fold, $p=0.058$ ) (Figure S3).

\subsubsection{The Pathway Enzyme Expression in Colonic Mucosa from CRC Patients and Normal} Colonic Tissue

As the molecular landscape is frequently altered also in macroscopically normal tissue adjacent to tumor $[29,30]$, we compared the expression level of pathway enzymes in tumors and tumor-adjacent non-cancerous tissue with that in normal colonic tissue obtained from patients undergoing polypectomy $(n=20)$.

The expression of ARG1, PRMT1 and PRMT5 was significantly elevated in both cancerous and non-cancerous tissue from CRC patients as compared to normal colonic mucosa. The expression of $D D A H 2$ was significantly elevated, and that of $D D A H 1$ non-significantly higher, exclusively in non-cancerous tumor-adjacent tissue (Figure 3). 


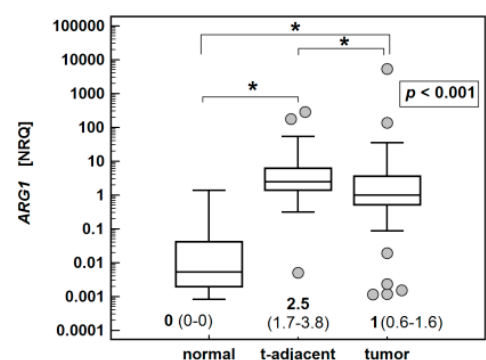

(a)

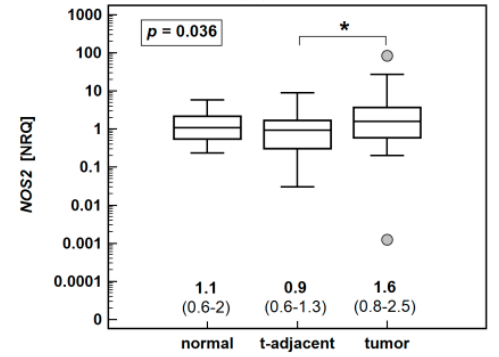

(d)

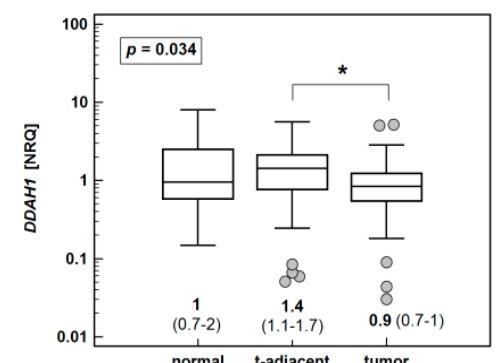

(b)

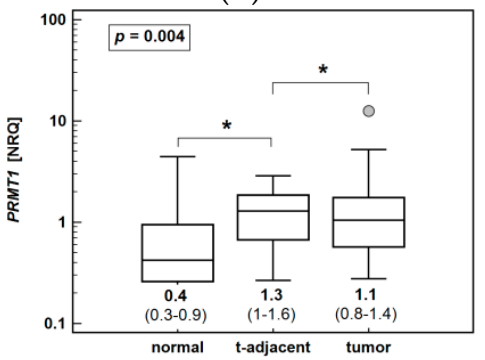

(e)

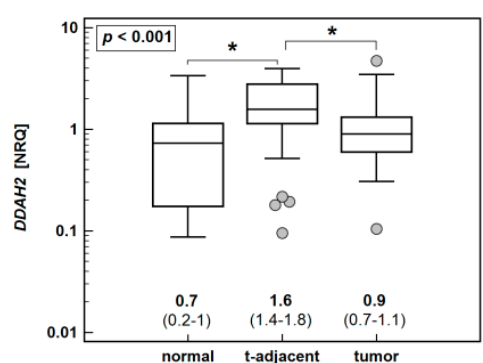

(c)

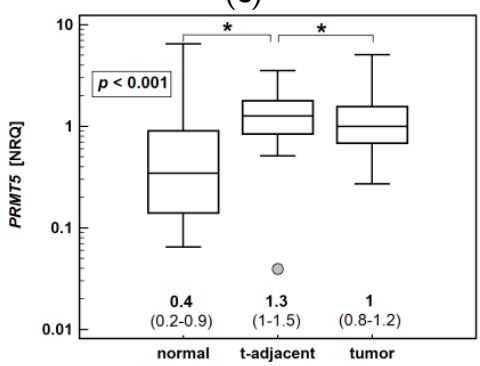

(f)

Figure 3. Comparison of arginine/nitric oxide pathway enzymes' expression in normal colonic tissue and tumor and non-cancerous tumor-adjacent tissue: (a) ARG1; (b) DDAH1; (c) DDAH2; (d) NOS2; (e) PRMT1; (f) PRMT2. Data analyzed using a Kruskal-Wallis $H$ test. Numeric data present medians of normalized relative quantities (NRQ), accompanied by 95\% confidence interval (CI). Boxes indicate median with interquartile range; whiskers-95\% CI; grey dots - outlying observations. *, significant between-group differences $(p<0.05) ; A R G 2$, arginase 2; DDAH, dimethylarginine dimethylaminohydrolase; NOS2, inducible nitric oxide synthase; PRMT, protein methyltransferase.

\subsection{Impact of Classic and Novel Oxicam Analogues on Arginine/NO Pathway}

To answer the question whether oxicam drugs can affect the status of arginine/NO pathway, Caco-2, HCT 116 and HT-29 cells were stimulated for $24 \mathrm{~h}$ with 5, 50 and $200 \mu \mathrm{M}$ concentration of classic (piroxicam and meloxicam) and novel oxicam drugs (compounds \#1-5). Drug concentration range was selected based on literature data $[21,24,31]$ and the results of sulforhodamine B (SRB) viability assay conducted in preliminary experiments (Figures S4-S6). In case of $5 \mu \mathrm{M}$ and $200 \mu \mathrm{M}$ concentration, an additional stimulation for 72 or $6 \mathrm{~h}$, respectively, was conducted.

\subsubsection{Arginine/NO Pathway Status in Colonic Adenocarcinoma Cell Lines}

First, we examined the expression level of pathway enzymes and the intracellular concentration of its metabolites in untreated cells (Figure 4).

The Caco-2 line had the highest expression of $A R G 2$ and DDAH2 and was the only line expressing NOS2 at quantifiable level. In turn, it had the lowest PRMTs levels. The HT-29 line had the lowest ARG2 and NOS2 expression and the highest DDAH1. The HCT 116 cells had the lowest ARG2 and $D D A H s$ and the highest PRMT5 expression (Figure 4a).

Of the investigated cell lines, Caco-2 had generally the lowest concentration of pathway metabolites and HCT 116 the highest. The exception was citrulline-higher in HT-29 than HCT 116; arginine-the lowest in HT-29; and ADMA-present at comparable level in both Caco-2 and HT-29 cells (Figure 4b). 


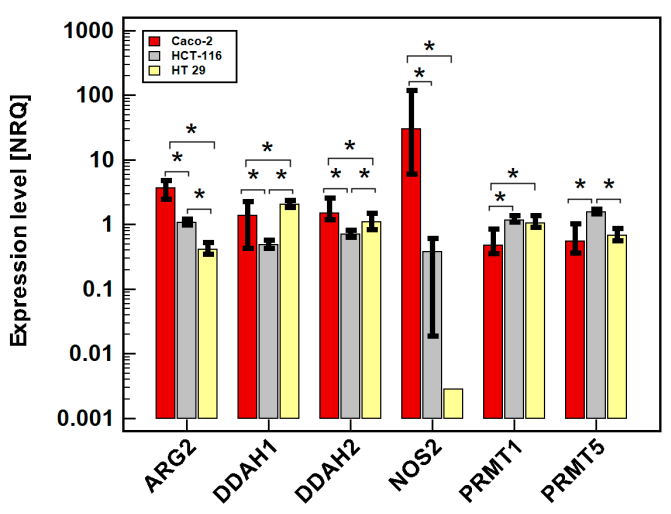

(a)

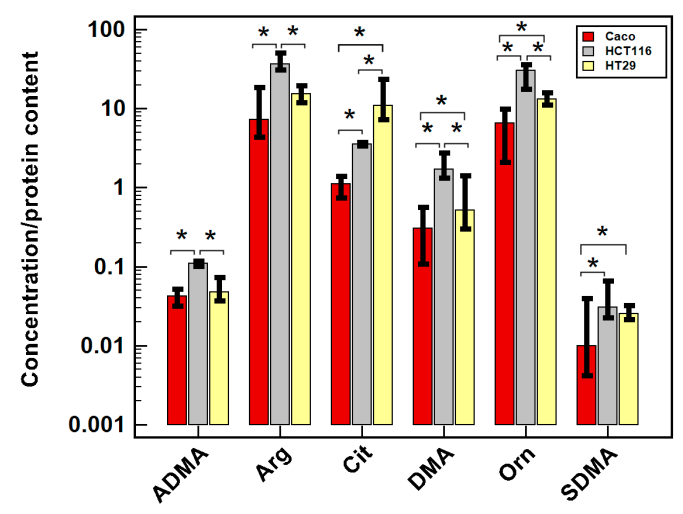

(b)

Figure 4. Comparison of arginine/nitric oxide pathway status in untreated colonic adenocarcinoma cell lines in 24-h cultures: (a) gene expression normalized to GAPDH; (b) intercellular metabolite concentration adjusted to protein content. Bars represent medians of normalized relative quantities (NRQ) with 95\% confidence interval (whiskers). Data were analyzed using Kruskal-Wallis $H$ test. *, significant between-group differences $(p<0.05) ; A R G 2$, arginase 2; DDAH, dimethylarginine dimethylaminohydrolase; NOS2, inducible nitric oxide synthase; PRMT, protein methyltransferase; ADMA, asymmetric dimethylarginine; Arg, arginine; Cit, citrulline; DMA, dimethylamine; Orn, ornithine; SDMA, symmetric dimethylamine.

\subsubsection{Effect of Oxicam Drugs on Gene Expression of Key Pathway Enzymes}

Pairwise analysis of treated and untreated cells showed piroxicam to have no significant effect on the expression of any examined genes (Table 1). Comparison of expression ratios (treated-to-untreated) at various drug concentrations showed no significant differences as well (Figures 5-7).

Meloxicam slightly downregulated the expression of DDAHs and PRMTs in HT-29. It also downregulated ARG2 in HCT 116 by two-fold at $200 \mu \mathrm{M}$ concentration while slightly upregulating it at $5 \mu \mathrm{M}$ (Table 1). The expression ratios in Caco-2 tended to increase along with increasing meloxicam concentration for the majority of investigated genes (Figure 5) but to decrease in HCT 116 (Figure 6) and HT-29 cells (Figure 7). Significant differences in expression ratios were observed regarding ARG2 in HCT 116 and HT-29 cells and regarding DDAH2 in HT-29 cells, as they were lower at higher drug concentrations.

The examined cell lines were more responsive to the novel oxicam analogues, particularly HCT 116 and HT-29 cells (Table 1).

The expression of $A R G 2$ tended to be slightly downregulated at lower and substantially upregulated at higher drug concentration. Compound \#1 at $200 \mu \mathrm{M}$ was its strongest inducer (Table 1). The ARG2 expression ratios increased along with increasing compounds' \#1-5 concentration, significantly so in HT-29 (Figure 7) and for compound \#2 in HCT 116 (Figure 6), and compounds \#4 and \#5 in Caco-2 (Figure 5).

Compounds \#1-3 and \#5 had negative impact on DDAHs expression, mainly in HT-29 cells and at $200 \mu \mathrm{M}$ concentration (Table 1). The DDAH1 expression ratio decreased along with increasing drug concentration, significantly so for compounds \#1-3 in HT-29 cells (Figure 7) and for compound \#3 in HCT 116 (Figure 6). The dose-dependent effect on DDAH2 expression in HT-29 cells was notable for compounds \#1-3, but significant solely for compound \#3 (Figure 7).

The NOS2 expression was quantifiable only in Caco-2 cells and was significantly upregulated by compounds \#1, \#2 and \#4 at $200 \mu \mathrm{M}$ concentration (Table 1). Dose-dependent effect was notable for compounds \#1-4 (Figure 5).

At $200 \mu \mathrm{M}$, compounds \#2-5 downregulated expression of PRMTs in HCT 116 and HT-29 cells and compounds \#2-3 also at $50 \mu \mathrm{M}$ concentration (Table 1). The PRMT1 expression ratios decreased along with increasing drug concentration, significantly so for compounds \#2 and \#3 in HCT 116 (Figure 6) 
and \#2, \#3, and \#5 in HT-29 cells (Figure 7). Likewise, the PRMT5 expression ratios decreased in a dose dependent-manner, significantly so for compounds \#2-4 in HCT 116 (Figure 6) and for compounds \#3 and \#4 in HT-29 (Figure 7).

Table 1. Effect of novel oxicam analogues on arginine/nitric oxide pathway enzymes.

\begin{tabular}{|c|c|c|c|c|c|c|c|c|c|c|}
\hline \multirow{2}{*}{ Gene } & \multirow{2}{*}{ Comp. } & \multicolumn{3}{|c|}{$5 \mu \mathrm{M}$} & \multicolumn{3}{|c|}{$50 \mu \mathrm{M}$} & \multicolumn{3}{|c|}{$200 \mu \mathrm{M}$} \\
\hline & & Caco2 & HCT & HT29 & Caco2 & HCT & HT29 & Caco2 & HCT & HT29 \\
\hline \multirow[t]{7}{*}{ ARG2 } & $\# 1$ & $\downarrow(1.1)$ & $\downarrow 1.2^{2}$ & $=$ & $=$ & $=$ & $\uparrow 3.8^{1}$ & $\uparrow 1.8^{1}$ & $\uparrow 3.9^{2}$ & $\uparrow 7.0^{2}$ \\
\hline & $\# 2$ & $=$ & $=$ & $=$ & $\downarrow 1.3^{1}$ & $=$ & $\uparrow 6.7^{1}$ & $=$ & $\uparrow 2.1^{1}$ & $\uparrow 6.4^{2}$ \\
\hline & $\# 3$ & $=$ & $\downarrow(1.3)$ & $\uparrow 1.5^{2}$ & $=$ & $=$ & $\uparrow 4.0^{1}$ & $=$ & $\uparrow 2.0^{1}$ & $\uparrow(4.3)$ \\
\hline & $\# 4$ & $=$ & $=$ & $=$ & $\downarrow 1.2^{1}$ & $=$ & $=$ & $\uparrow 3.9^{1}$ & $=$ & $\uparrow 3.8^{2}$ \\
\hline & \#5 & $=$ & $=$ & $\downarrow(1.6)$ & $\downarrow(1.4)$ & $=$ & $=$ & $=$ & $=$ & $\uparrow(7.0)$ \\
\hline & $\mathrm{P}$ & $=$ & $=$ & $=$ & $=$ & $=$ & $=$ & $=$ & $=$ & $=$ \\
\hline & M & $=$ & $\uparrow 1.2^{1}$ & $=$ & $=$ & $=$ & $=$ & $=$ & $\downarrow 2.0^{2}$ & $=$ \\
\hline \multirow[t]{7}{*}{ DDAH1 } & $\# 1$ & $=$ & $=$ & $=$ & $=$ & $=$ & $\downarrow 1.9^{1}$ & $=$ & $=$ & $\downarrow 1.9^{1}$ \\
\hline & $\# 2$ & $=$ & $=$ & $=$ & $\downarrow 1.7^{1}$ & $\downarrow 2.0^{1}$ & $=$ & $=$ & $\downarrow 1.7^{2}$ & $\downarrow 2.4^{1}$ \\
\hline & $\# 3$ & $=$ & $=$ & $\uparrow(1.3)$ & $=$ & $\downarrow(1.6)$ & $\downarrow(2.3)$ & $=$ & $\downarrow 2.2^{1}$ & $\downarrow 3.7^{1}$ \\
\hline & $\# 4$ & $=$ & $=$ & $=$ & $=$ & $=$ & $=$ & $=$ & $=$ & $=$ \\
\hline & $\# 5$ & $=$ & $=$ & $=$ & $=$ & $=$ & $=$ & $=$ & $=$ & $\downarrow 3.0^{1}$ \\
\hline & $\mathrm{P}$ & $=$ & $=$ & $=$ & $=$ & $=$ & $=$ & $=$ & $=$ & $=$ \\
\hline & M & $=$ & $=$ & $\downarrow 1.2^{1}$ & $=$ & $=$ & $=$ & $=$ & $=$ & $\downarrow(1.3)$ \\
\hline \multirow[t]{7}{*}{ DDAH2 } & $\# 1$ & $=$ & $\downarrow 1.1^{1}$ & $=$ & $=$ & $=$ & $\downarrow 1.5^{1}$ & $\downarrow 1.4^{1}$ & $=$ & $\downarrow(1.9)$ \\
\hline & $\# 2$ & $=$ & $\downarrow 1.5^{1}$ & $=$ & $=$ & $=$ & $=$ & $=$ & $=$ & $\downarrow 2.1^{1}$ \\
\hline & $\# 3$ & $=$ & $=$ & $\uparrow 1.4^{2}$ & $=$ & $=$ & $=$ & $=$ & $=$ & $\downarrow(3.0)$ \\
\hline & $\# 4$ & $=$ & $\downarrow 1.2^{1}$ & $=$ & $=$ & $\downarrow 1.6^{1}$ & $=$ & $=$ & $=$ & $=$ \\
\hline & $\# 5$ & $=$ & $=$ & $\downarrow(1.3)$ & $=$ & $=$ & $=$ & $=$ & $=$ & $\downarrow 1.5^{1}$ \\
\hline & $\mathrm{P}$ & $=$ & $=$ & $=$ & $=$ & $=$ & $=$ & $=$ & $=$ & $=$ \\
\hline & M & $=$ & $=$ & $=$ & $=$ & $=$ & $=$ & $=$ & $=$ & $\downarrow 1.8^{1}$ \\
\hline \multirow[t]{7}{*}{ NOS2 } & $\# 1$ & $=$ & - & - & $=$ & - & - & $\uparrow 2.2^{1}$ & - & - \\
\hline & $\# 2$ & $=$ & - & - & $\downarrow(1.7)$ & - & - & $\uparrow 3.3^{2}$ & - & - \\
\hline & \#3 & $=$ & - & - & $=$ & - & - & $=$ & - & - \\
\hline & $\# 4$ & $=$ & - & - & $=$ & - & - & $\uparrow 2.9^{1}$ & - & - \\
\hline & \#5 & $=$ & - & - & $=$ & - & - & $\uparrow(1.9)$ & - & - \\
\hline & $\mathrm{P}$ & $=$ & - & - & $=$ & - & - & $=$ & - & - \\
\hline & M & $=$ & - & - & $=$ & - & - & $=$ & - & - \\
\hline \multirow[t]{7}{*}{ PRMT1 } & $\# 1$ & $=$ & $=$ & $\uparrow 1.8^{2}$ & $=$ & $=$ & $=$ & $=$ & $=$ & $\downarrow(1.5)$ \\
\hline & $\# 2$ & $=$ & $=$ & $=$ & $\downarrow(1.7)$ & $\downarrow 2.1^{1}$ & $\downarrow(1.6)$ & $=$ & $\downarrow 2.3^{2}$ & $\downarrow 2.4^{2}$ \\
\hline & $\# 3$ & $=$ & $=$ & $=$ & $=$ & $\downarrow 1.8^{1}$ & $\downarrow 2.1^{2}$ & $=$ & $\downarrow 3.3^{1}$ & $\downarrow 4.6^{2}$ \\
\hline & $\# 4$ & $=$ & $=$ & $=$ & $\downarrow 1.2^{1}$ & $=$ & $=$ & $=$ & $=$ & $\downarrow(2.0)$ \\
\hline & $\# 5$ & $=$ & $=$ & $=$ & $=$ & $=$ & $=$ & $=$ & $=$ & $\downarrow 3.2^{1}$ \\
\hline & $\mathrm{P}$ & $=$ & $=$ & $=$ & $=$ & $=$ & $=$ & $=$ & $=$ & $=$ \\
\hline & $\mathrm{M}$ & $=$ & $=$ & $\downarrow 1.1^{1}$ & $=$ & $=$ & $=$ & $=$ & $=$ & $\downarrow(1.1)$ \\
\hline \multirow[t]{7}{*}{ PRMT5 } & $\# 1$ & $=$ & $=$ & $\uparrow 1.5^{1}$ & $=$ & $\downarrow(1.4)$ & $=$ & $\uparrow 1.6^{2}$ & $=$ & $=$ \\
\hline & $\# 2$ & $=$ & $=$ & $=$ & $\downarrow 1.4^{1}$ & $\downarrow 2.1^{1}$ & $=$ & $=$ & $\downarrow 2.6^{1}$ & $\downarrow 1.7^{1}$ \\
\hline & $\# 3$ & $=$ & $=$ & $\uparrow 1.2^{1}$ & $\downarrow 1.5^{1}$ & $\downarrow 1.9^{1}$ & $=$ & $=$ & $\downarrow 3.6^{2}$ & $\downarrow 3.2^{2}$ \\
\hline & $\# 4$ & $=$ & $=$ & $=$ & $=$ & $=$ & $=$ & $=$ & $\downarrow 3.8^{1}$ & $\downarrow 2.0^{1}$ \\
\hline & $\# 5$ & $=$ & $=$ & $\downarrow(1.3)$ & $=$ & $=$ & $=$ & $=$ & $=$ & $\downarrow 2.4^{1}$ \\
\hline & $\mathrm{P}$ & $\downarrow(1.3)$ & $=$ & $=$ & $=$ & $=$ & $=$ & $=$ & $=$ & $=$ \\
\hline & M & $=$ & $=$ & $=$ & $=$ & $=$ & $=$ & $=$ & $=$ & $\downarrow 1.2^{2}$ \\
\hline
\end{tabular}

Results of paired analysis showing a relative increase $(\uparrow)$ or decrease $(\downarrow)$ in gene expression normalized to $G A P D H$ in treated as compared to non-treated cells (24-h incubation with indicated drug concentration). Data are presented as mean of three independent experiments and were analyzed using $t$-test for paired samples. Comp., compound; HCT, HCT 116 cell line; P, piroxicam; M, meloxicam; ARG2, arginase 2; DDAH, dimethylarginine dimethylaminohydrolase; NOS2, inducible nitric oxide synthase; $P R M T$, protein methyltransferase. ${ }^{1} p<0.05$; ${ }^{2} p<0.01$; =, no significant difference or tendency $(p \geq 0.1)$; - non-quantifiable. Tendencies $(0.05<p<0.1)$ are given in brackets. Magnitude of relative change is shown in the form of a three-color-scaled heatmap (red-yellow-green, scaled from: -7.0 (dark red), through 1.0 (yellow) to 7.0 (dark green). 


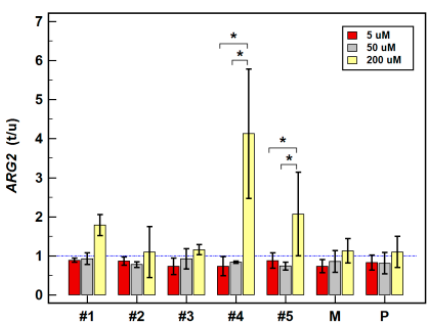

(a)

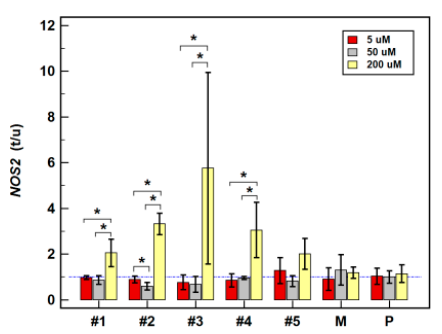

(d)

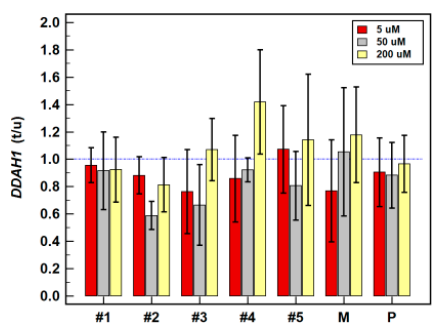

(b)

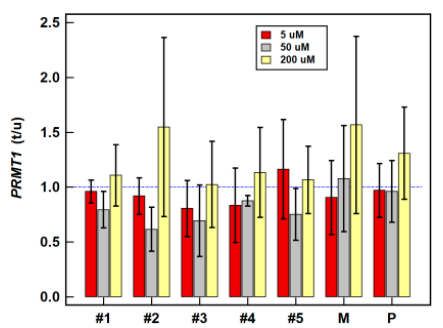

(e)

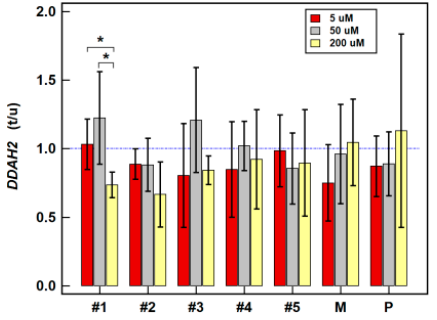

(c)

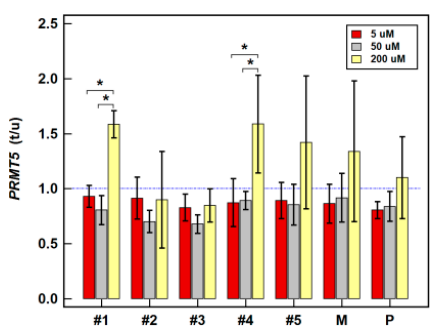

(f)

Figure 5. Dose-dependent effect of oxicams on enzyme gene expression in Caco-2 cells stimulated with 5, 50 and $200 \mu \mathrm{M}$ drug concentrations for 24 h: (a) Arginase-2 (ARG2); (b) Dimethylarginine dimethylaminohydrolase-1 (DDAH1); (c) Dimethylarginine dimethylaminohydrolase-2 (DDAH2); (d) Nitric oxide synthase-2 (NOS2); (e) Protein methyltransferase-1 (PRMT1); (f) Protein methyltransferase-5 (PRMT5). Bars represent mean $(n=3)$ concentration ratios treated-to-untreated cells $(\mathrm{t} / \mathrm{u})$ with standard deviation (whiskers). No effect is marked by horizontal blue reference line. Data were analyzed using one-way analysis of variance. * , significant between-group differences; \#1-5, oxicam analogues; $\mathrm{M}$, meloxicam; $\mathrm{P}$, piroxicam.

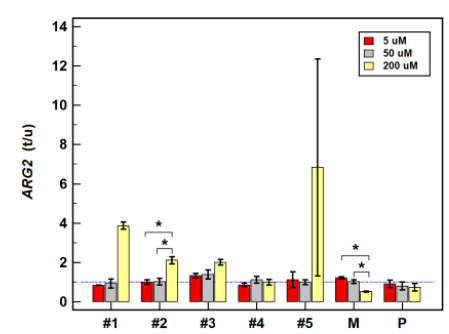

(a)

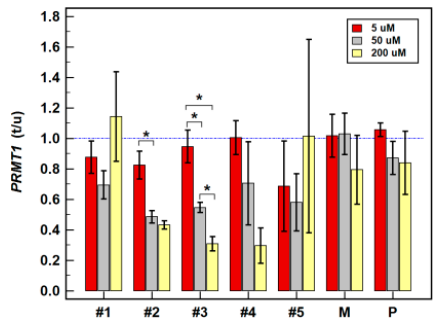

(d)

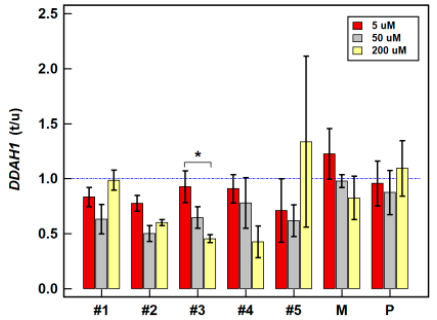

(b)

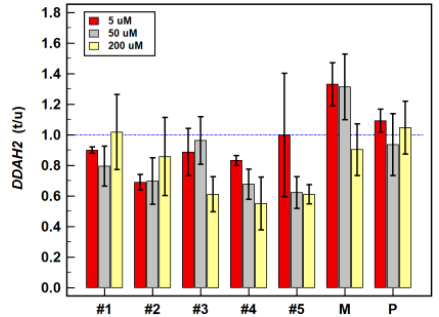

(c)

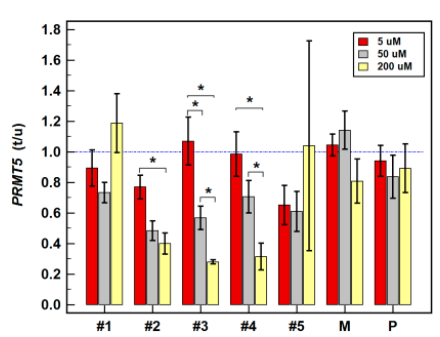

(e)

Figure 6. Dose-dependent effect of oxicams on enzyme gene expression in HCT 116 cells stimulated with 5, 50 and $200 \mu \mathrm{M}$ drug concentrations for $24 \mathrm{~h}$ : (a) Arginase-2 (ARG2); (b) Dimethylarginine dimethylaminohydrolase-1 (DDAH1); (c) Dimethylarginine dimethylaminohydrolase-2 (DDAH2); (d) Protein methyltransferase-1 (PRMT1); (e) Protein methyltransferase-5 (PRMT5). Bars represent mean $(n=3)$ concentration ratios treated-to-untreated cells $(\mathrm{t} / \mathrm{u})$ with standard deviation (whiskers). No effect is marked by horizontal blue reference line. Data were analyzed using one-way analysis of variance. * , significant between-group differences; \#1-5, oxicam analogues; $\mathrm{M}$, meloxicam; $\mathrm{P}$, piroxicam. 


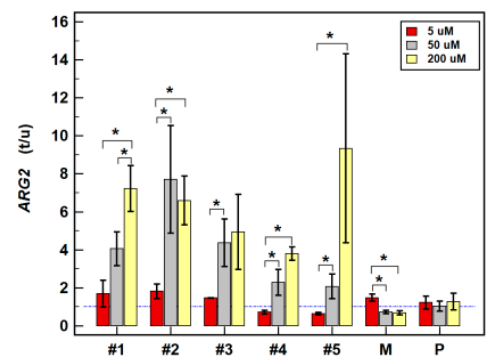

(a)

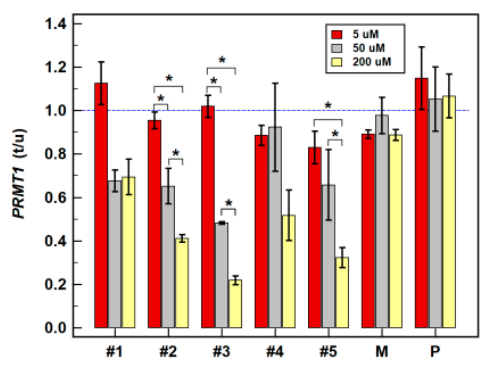

(d)

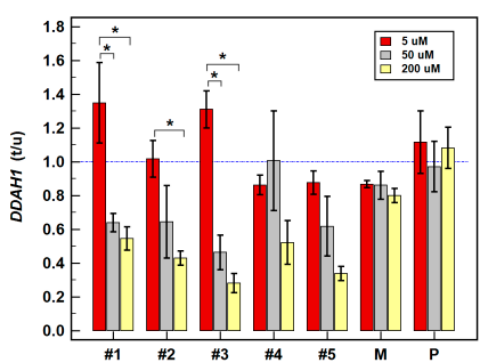

(b)

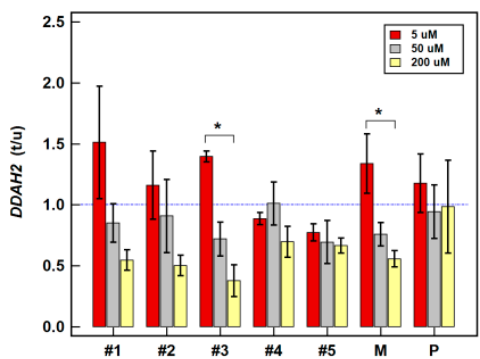

(c)

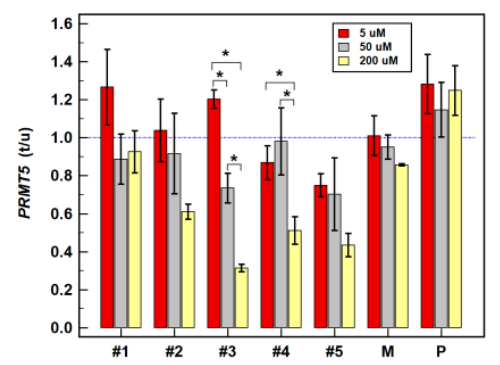

(e)

Figure 7. Dose-dependent effect of oxicams on enzyme gene expression in HT-29 cells stimulated with 5, 50 and $200 \mu \mathrm{M}$ drug concentrations for $24 \mathrm{~h}$ : (a) Arginase-2 (ARG2); (b) Dimethylarginine dimethylaminohydrolase-1 (DDAH1); (c) Dimethylarginine dimethylaminohydrolase-2 (DDAH2); (d) Protein methyltransferase-1 (PRMT1); (e) Protein methyltransferase-5 (PRMT5). Bars represent mean $(n=3)$ concentration ratios treated-to-untreated cells $(\mathrm{t} / \mathrm{u})$ with standard deviation (whiskers). No effect is marked by horizontal blue reference line. Data were analyzed using one-way analysis of variance. * significant between-group differences; \#1-5, oxicam analogues; M, meloxicam; P, piroxicam.

In addition, the effect of oxicams on cancer cells during longer stimulation with low drug concentration (72-h, $5 \mu \mathrm{M})$ or during shorter stimulation with high drug concentration (6-h, $200 \mu \mathrm{M})$ was evaluated. Prolonged stimulation with low meloxicam concentration slightly decreased, or tended to decrease, ARG2 and DDAH2 expression in HCT 116 and HT-29 cells and PRMT5 in HCT 116 cells. Compound \#4 tended to downregulate ARG2 and PRMT5. Shorter stimulation with high drug concentration upregulated ARG2 expression in HCT 116 (compound \#1 by 1.6-fold) and HT-29 cells (compound \#3 by 3.5-fold and compound \#5 by 2.6-fold while compounds \#1 and \#2 displayed a similar tendency) (Table S1).

\subsubsection{Effect of Oxicam Drugs on Enzyme Protein Expression in HT-29 Cells}

As the examined oxicam drugs had the most pronounced effect on HT-29 cells, this line was chosen to seek confirmation of drug effect on protein level. Western-blot analysis showed that at $200 \mu \mathrm{M}$, compounds \#1, \#2, \#4 and \#5 upregulated arginase-2 protein expression as compared to untreated HT-29 cells (Figure S7). When normalized to total protein, allowing for adjustment against differences in gel loading and transfer efficiency, they upregulated arginase- 2 concentration by 128, 1.2, 11, and 17.1-fold. Piroxicam upregulated and meloxicam downregulated arginase- 2 by 2.7 and 12.7-fold, respectively. Except for compound \#5, upregulating arginase- 2 by 2.7 -fold, $5 \mu \mathrm{M}$ drug concentrations had negative impact on the enzyme expression. Compound \#1 downregulated arginase- 2 protein expression by 5.9 -fold, compounds \#2 and \#3 by 7.7-fold, and piroxicam and meloxicam by 1.5 and 9.4-fold, respectively.

Compounds \#1-5 downregulated DDAH1 and DDAH2 protein expression at $200 \mu \mathrm{M}$ (Figure S7) by $2.2,22.8,72.8,4.4$, and 299-fold (DDAH1) and by 10.8, 29.5, 8.9, 2.6, and 24.3-fold (DDAH2), respectively. Piroxicam downregulated DDAH1 protein by 1.9-fold and DDAH2 by 3.6-fold. Meloxicam downregulated DDAH2 as well (by 1.9-fold). 
Likewise, oxicam drugs at $200 \mu \mathrm{M}$ concentration downregulated PRMTs (Figure S7). Compounds \#1-3 and piroxicam were more effective in case of PRMT1 (downregulation by 10.8, 29.5, 8.9, and 3.6-fold for PRMT1 and 2.4, 1.7, 1.4, and 1.9-fold for PRMT5, respectively) and compounds \#4 and \#5 in case of PRMT5 (downregulation by 2.6 and 24.3-fold for PRMT1 and by 19.7 and 50-fold for PRMT5, respectively). Meloxicam had no substantial effect on PRMT1 and upregulated PRMT5 by 1.8-fold.

\subsubsection{Effect of Oxicam Drugs on Intracellular Concentrations of Key Pathway Metabolites}

Pairwise analysis of treated as compared to non-treated cells showed mostly positive drug effect on metabolite accumulation, especially at 50 and $200 \mu \mathrm{M}$ concentration (Table 2).

Table 2. Effect of Classic and Novel Oxicam Analogues on the Intracellular Level of Key Metabolites of Arginine/Nitric Oxide Pathway.

\begin{tabular}{|c|c|c|c|c|c|c|c|c|c|c|}
\hline \multirow{2}{*}{ Gene } & \multirow{2}{*}{ Comp. } & \multicolumn{3}{|c|}{$5 \mu \mathbf{M}$} & \multicolumn{3}{|c|}{$50 \mu \mathrm{M}$} & \multicolumn{3}{|c|}{$200 \mu \mathrm{M}$} \\
\hline & & Caco2 & НСТ & HT29 & Caco2 & НСТ & НT29 & Caco2 & HCT & НТ29 \\
\hline \multirow[t]{7}{*}{ Arg } & $\# 1$ & $=$ & $=$ & $=$ & $\uparrow(1.4)$ & $\uparrow 2.3^{1}$ & $\uparrow 2.8^{1}$ & $=$ & $\uparrow 2.6^{1}$ & $\uparrow 4.2^{1}$ \\
\hline & $\# 2$ & $=$ & $=$ & $=$ & $\uparrow(1.5)$ & $\uparrow 2.6^{2}$ & $\uparrow 3.4^{1}$ & $\uparrow(2.2)$ & $\uparrow 2.3^{1}$ & $\uparrow 2.9^{1}$ \\
\hline & $\# 3$ & $\uparrow 1.4^{1}$ & $=$ & $=$ & $\uparrow(1.8)$ & $\uparrow 2.1^{1}$ & $\uparrow 3.7^{2}$ & $\uparrow 1.3^{2}$ & $\uparrow 2.2^{2}$ & $\uparrow(2.1)$ \\
\hline & $\# 4$ & $\uparrow(1.3)$ & $=$ & $\downarrow(1.4)$ & $\uparrow 1.4^{2}$ & $\uparrow(1.6)$ & $\uparrow(2.0)$ & $\uparrow 1.5^{2}$ & $=$ & $\uparrow 3.3^{1}$ \\
\hline & $\# 5$ & $\uparrow 1.2^{1}$ & $=$ & $\downarrow(1.7)$ & $\uparrow(1.5)$ & $=$ & $=$ & $\downarrow 2.2^{1}$ & $=$ & $=$ \\
\hline & $\mathrm{P}$ & $\uparrow 1.4^{1}$ & $=$ & $=$ & $\uparrow(1.5)$ & $=$ & $=$ & $=$ & $=$ & $=$ \\
\hline & M & $\uparrow 1.5^{2}$ & $=$ & $=$ & $\uparrow 1.6^{1}$ & $=$ & $=$ & $=$ & $=$ & $=$ \\
\hline \multirow[t]{7}{*}{ Cit } & $\# 1$ & $=$ & $=$ & $=$ & $=$ & $=$ & $=$ & $\uparrow 1.5^{2}$ & $=$ & $=$ \\
\hline & $\# 2$ & $=$ & $=$ & $\uparrow 1.3^{1}$ & $=$ & $=$ & $=$ & $\uparrow 1.8^{1}$ & $\uparrow 2.1^{1}$ & $=$ \\
\hline & $\# 3$ & $\uparrow(1.1)$ & $=$ & $=$ & $=$ & $\uparrow(2.0)$ & $\uparrow(3.2)$ & $\uparrow 1.5^{2}$ & $\uparrow 2.2^{1}$ & $=$ \\
\hline & $\# 4$ & $=$ & $=$ & $=$ & $=$ & $=$ & $=$ & $=$ & $=$ & $=$ \\
\hline & \#5 & $=$ & $=$ & $=$ & $=$ & $=$ & $=$ & $=$ & $=$ & $=$ \\
\hline & $\mathrm{P}$ & $=$ & $=$ & $=$ & $=$ & $=$ & $=$ & $=$ & $=$ & $=$ \\
\hline & M & $=$ & $=$ & $=$ & $=$ & $=$ & $=$ & $=$ & $=$ & $=$ \\
\hline \multirow[t]{7}{*}{ Orn } & $\# 1$ & $\downarrow(1.1)$ & $=$ & $=$ & $=$ & $=$ & $\uparrow(1.6)$ & $\uparrow 2.3^{2}$ & $=$ & $\uparrow 1.8^{1}$ \\
\hline & $\# 2$ & $=$ & $=$ & $=$ & $=$ & $\uparrow 2.7^{1}$ & $=$ & $=$ & $\uparrow 2.3^{2}$ & $\uparrow(1.6)$ \\
\hline & $\# 3$ & $\uparrow 1.1^{1}$ & $=$ & $=$ & $=$ & $\uparrow(2.2)$ & $\uparrow(1.6)$ & $=$ & $\uparrow 2.3^{1}$ & $=$ \\
\hline & $\# 4$ & $=$ & $=$ & $=$ & $=$ & $=$ & $=$ & $=$ & $=$ & $=$ \\
\hline & $\# 5$ & $=$ & $=$ & $=$ & $=$ & $\uparrow(1.9)$ & $=$ & $=$ & $\uparrow(2.9)$ & $\uparrow(1.3)$ \\
\hline & $\mathrm{P}$ & $\uparrow(1.1)$ & $=$ & $\downarrow(1.1)$ & $=$ & $=$ & $=$ & $=$ & $=$ & $=$ \\
\hline & $\mathrm{M}$ & $=$ & $\uparrow 2.3^{1}$ & $=$ & $=$ & $=$ & $=$ & $=$ & $=$ & $=$ \\
\hline \multirow[t]{7}{*}{ ADMA } & $\# 1$ & $=$ & $=$ & $=$ & $=$ & $=$ & $\uparrow 2.2^{2}$ & $\uparrow 1.3^{1}$ & $\uparrow(1.8)$ & $\uparrow(2.3)$ \\
\hline & $\# 2$ & $=$ & $=$ & $\uparrow 1.7^{1}$ & $=$ & $\uparrow(2.2)$ & $\uparrow(2.9)$ & $\uparrow 1.7^{2}$ & $\uparrow 2.2^{1}$ & $=$ \\
\hline & $\# 3$ & $=$ & $=$ & $=$ & $=$ & $=$ & $\uparrow(3.0)$ & $\uparrow 1.5^{1}$ & $\uparrow 2.1^{2}$ & $=$ \\
\hline & $\# 4$ & $=$ & $=$ & $=$ & $=$ & $=$ & $=$ & $\uparrow(1.1)$ & $=$ & $=$ \\
\hline & $\# 5$ & $=$ & $=$ & $=$ & $=$ & $=$ & $=$ & $=$ & $=$ & $=$ \\
\hline & $\mathrm{P}$ & $=$ & $=$ & $=$ & $=$ & $=$ & $=$ & $=$ & $=$ & $=$ \\
\hline & $\mathrm{M}$ & $=$ & $=$ & $=$ & $=$ & $=$ & $=$ & $=$ & $=$ & $\uparrow 1.7^{1}$ \\
\hline \multirow[t]{7}{*}{ SDMA } & $\# 1$ & $=$ & $=$ & $=$ & $=$ & $\uparrow 2.6^{1}$ & $\uparrow 2.6^{1}$ & $\uparrow 3.2^{1}$ & $\uparrow 2.5^{1}$ & $\uparrow 2.6^{1}$ \\
\hline & $\# 2$ & $=$ & $=$ & $=$ & $=$ & $\uparrow 2.4^{1}$ & $\uparrow 2.6^{1}$ & $\uparrow 2.0^{1}$ & $\uparrow 2.2^{1}$ & $\uparrow 2.3^{1}$ \\
\hline & $\# 3$ & $\uparrow 1.1^{2}$ & $=$ & $=$ & $\uparrow(1.3)$ & $=$ & $\uparrow 2.6^{1}$ & $=$ & $\uparrow(1.9)$ & $\uparrow(1.8)$ \\
\hline & $\# 4$ & $=$ & $=$ & $=$ & $=$ & $=$ & $=$ & $\uparrow 1.7^{2}$ & $=$ & $\uparrow 2.0^{1}$ \\
\hline & $\# 5$ & $=$ & $=$ & $=$ & $=$ & $=$ & $\uparrow 1.4^{2}$ & $=$ & $=$ & $=$ \\
\hline & $\mathrm{P}$ & $=$ & $=$ & $=$ & $=$ & $=$ & $=$ & $\uparrow 1.2^{1}$ & $=$ & $=$ \\
\hline & M & $=$ & $=$ & $=$ & $=$ & $=$ & $=$ & $=$ & $=$ & $=$ \\
\hline \multirow[t]{7}{*}{ DMA } & $\# 1$ & $=$ & $=$ & $=$ & $=$ & $=$ & $=$ & $=$ & $=$ & $\uparrow(1.3)$ \\
\hline & $\# 2$ & $=$ & $=$ & $=$ & $\uparrow(1.1)$ & $\uparrow(2.3)$ & $=$ & $=$ & $=$ & $=$ \\
\hline & $\# 3$ & $=$ & $=$ & $=$ & $=$ & $\uparrow(2.1)$ & $=$ & $=$ & $\uparrow(2.7)$ & $=$ \\
\hline & $\# 4$ & $=$ & $=$ & $=$ & $\downarrow 1.1^{1}$ & $=$ & $=$ & $=$ & $=$ & $=$ \\
\hline & $\# 5$ & $=$ & $=$ & $=$ & $=$ & $=$ & $=$ & $=$ & $=$ & $=$ \\
\hline & $\mathrm{P}$ & $\uparrow(1.1)$ & $=$ & $=$ & $=$ & $=$ & $\downarrow 2.1^{1}$ & $=$ & $=$ & $=$ \\
\hline & $\mathrm{M}$ & $=$ & $=$ & $\downarrow 2.9^{1}$ & $=$ & $=$ & $=$ & $=$ & $=$ & $\downarrow(1.8)$ \\
\hline
\end{tabular}

Results of paired analysis showing a relative increase $(\uparrow)$ or decrease $(\downarrow)$ in metabolite concentration normalized to protein content in treated as compared to non-treated cells (24-h incubation with indicated drug concentration). Data are presented as mean of three independent experiments and were analyzed using $t$-test for paired samples. Comp., compound; HCT, HCT 116 cell line; P, piroxicam; M, meloxicam; Arg, arginine; Cit, citrulline; Orn, ornithine; ADMA, asymmetric dimethylarginine; SDMA, symmetric dimethylarginine; DMA, dimethylamine; $\mathrm{P}$, piroxicam; $\mathrm{M}$, meloxicam. ${ }^{1} p<0.05{ }^{2} p<0.01 ;=$, no significant difference or tendency $(p \geq 0.1)$; - non-quantifiable. Tendencies $(0.05<p<0.1)$ are given in brackets. Magnitude of relative change is shown in the form of a three-color-scaled heatmap (red-yellow-green, scaled from: -7.0 (dark red), through 1.0 (yellow) to 7.0 (dark green). 
Piroxicam caused minor accumulation of arginine at $5 \mu \mathrm{M}$ concentration and upregulation of SDMA at $200 \mu \mathrm{M}$ concentration in Caco-2 cells, while downregulating DMA by 2.1-fold in HCT 116 at $50 \mu \mathrm{M}$ concentration (Table 2). The expression ratio of arginine at $200 \mu \mathrm{M}$ drug concentration was significantly lower in Caco-2 cells and that of SDMA was higher (Figure 8). The expression ratios of ADMA and citrulline in HT-29 cells were lower as well (Figure 9).

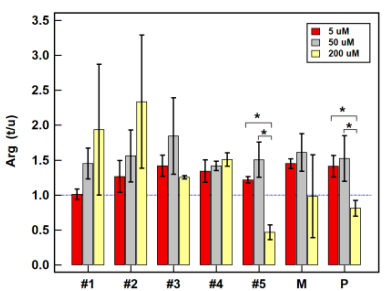

(a)

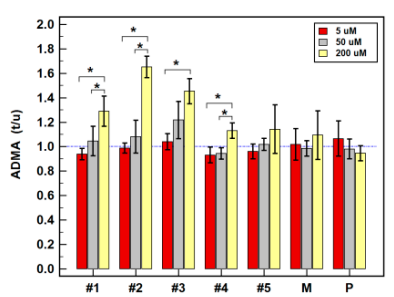

(d)

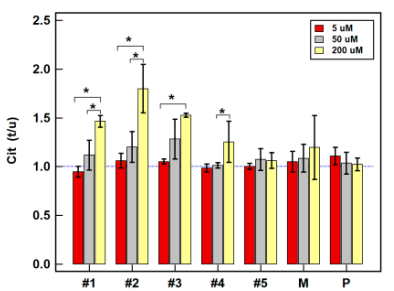

(b)

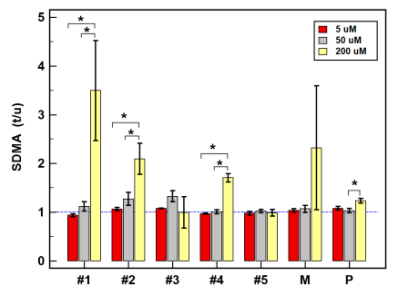

(e)

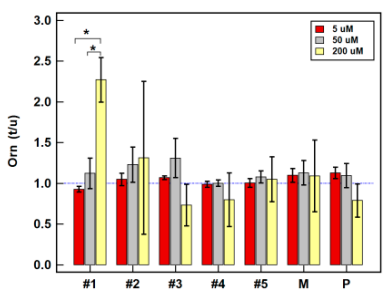

(c)

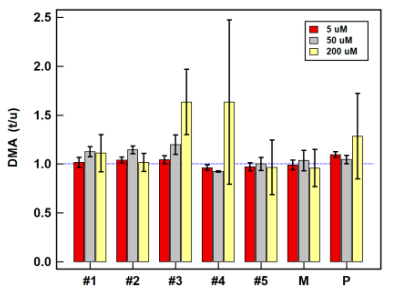

(f)

Figure 8. Dose-dependent effect of oxicams on the intracellular metabolite concentration in Caco-2 cells stimulated with 5, 50 and $200 \mu \mathrm{M}$ drug concentrations for $24 \mathrm{~h}$ : (a) Arginine (Arg); (b) Citrulline (Cit); (c) Ornithine (Orn); (d) Asymmetric dimethylarginine (ADMA); (e) Symmetric dimethylarginine (SDMA); (f) Dimethylamine (DMA). Bars represent mean $(n=3)$ concentration ratios treated-to-untreated cells $(t / u)$ with standard deviation (whiskers). No effect is marked by horizontal blue reference line. Data were analyzed using one-way analysis of variance. * significant between-group differences; \#1-5, oxicam analogues; $\mathrm{M}$, meloxicam; $\mathrm{P}$, piroxicam.

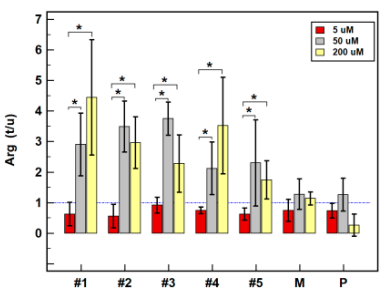

(a)

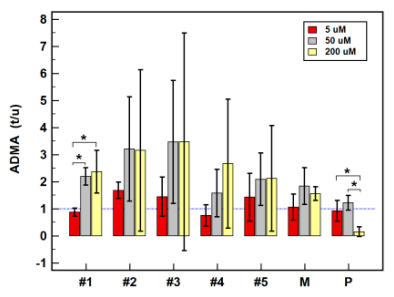

(d)

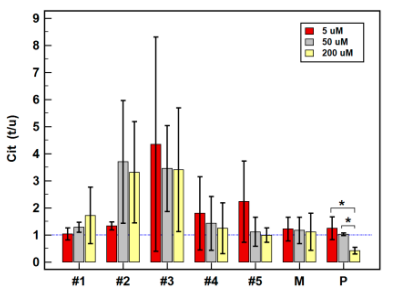

(b)

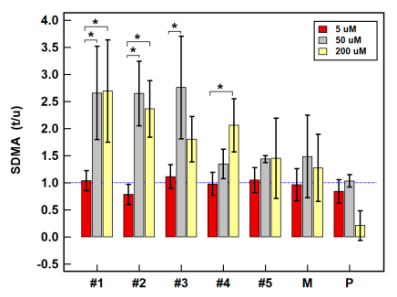

(e)

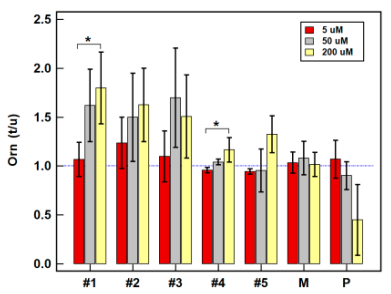

(c)

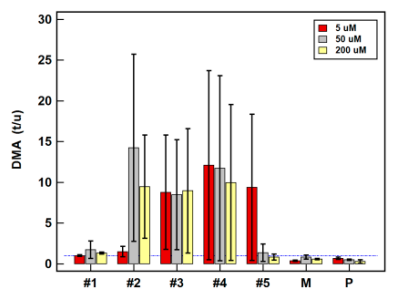

(f)

Figure 9. Dose-dependent effect of oxicams on the intracellular metabolite concentration in HT-29 cells stimulated with 5, 50 and $200 \mu \mathrm{M}$ drug concentrations for $24 \mathrm{~h}$ : (a) Arginine (Arg); (b) Citrulline (Cit); (c) Ornithine (Orn); (d) Asymmetric dimethylarginine (ADMA); (e) Symmetric dimethylarginine (SDMA); (f) Dimethylamine (DMA). Bars represent mean $(n=3)$ concentration ratios treated-to-untreated cells $(t / u)$ with standard deviation (whiskers). No effect is marked by horizontal blue reference line. Data were analyzed using one-way analysis of variance. * significant between-group differences; \#1-5, oxicam analogues; $\mathrm{M}$, meloxicam; $\mathrm{P}$, piroxicam. 
Meloxicam, at 5 and $50 \mu \mathrm{M}$ concentration, slightly upregulated intracellular arginine level. At $5 \mu \mathrm{M}$ concentration, it contributed to 2.3-fold accumulation of ornithine in HCT 116 while at $200 \mu \mathrm{M}$ concentration, it upregulated ADMA by 1.7-fold. The DMA in HT-29 was downregulated by meloxicam at $5 \mu \mathrm{M}$ concentration and similar tendency could be observed at $200 \mu \mathrm{M}$ of drug concentration (Table 2). However, no significant dose-dependent effect could be observed (Figures 8-10).

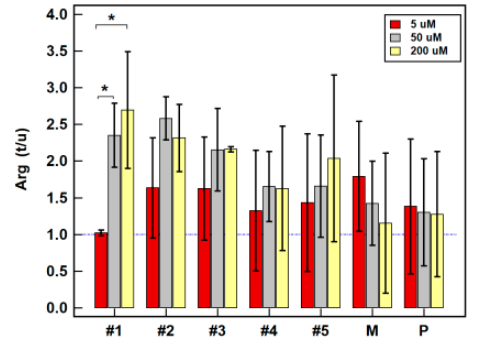

(a)

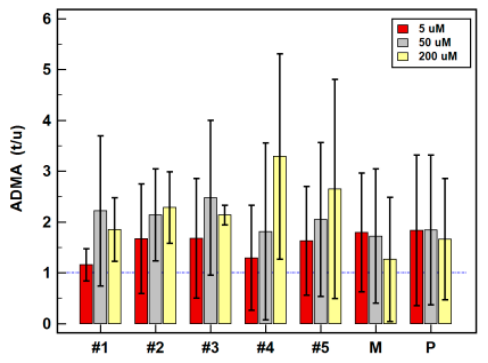

(d)

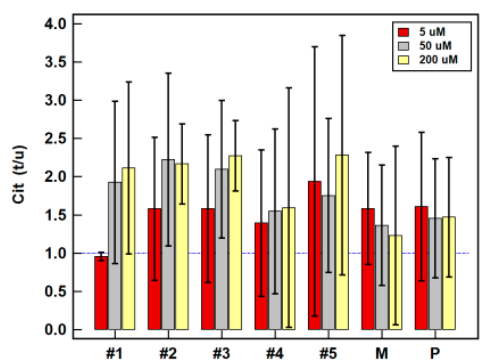

(b)

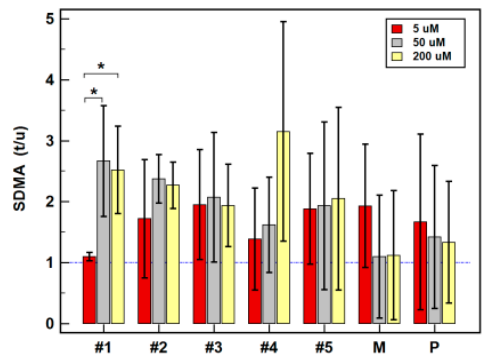

(e)

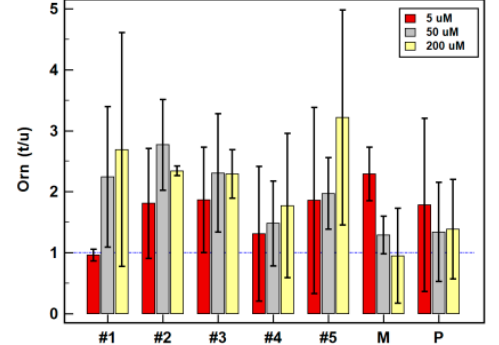

(c)

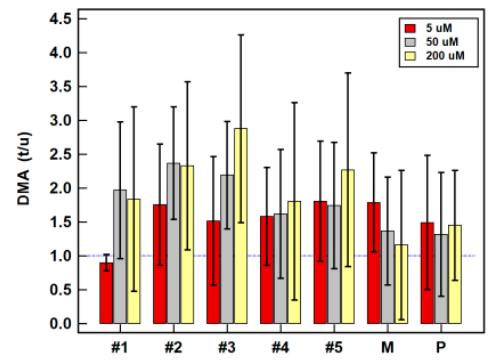

(f)

Figure 10. Dose-dependent effect of oxicams on the intracellular metabolite concentration in HCT 116 cells stimulated with 5, 50 and $200 \mu \mathrm{M}$ drug concentrations for $24 \mathrm{~h}$ : (a) Arginine (Arg); (b) Citrulline (Cit); (c) Ornithine (Orn); (d) Asymmetric dimethylarginine (ADMA); (e) Symmetric dimethylarginine (SDMA); (f) Dimethylamine (DMA). Bars represent mean $(n=3)$ concentration ratios treated-to-untreated cells $(t / u)$ with standard deviation (whiskers). No effect is marked by horizontal blue reference line. Data were analyzed using one-way analysis of variance. * , significant between-group differences; \#1-5, oxicam analogues; $\mathrm{M}$, meloxicam; $\mathrm{P}$, piroxicam.

Non-classic oxicams had a more pronounced effect on intracellular metabolite accumulation (Table 2). Arginine was upregulated, to varying degree, by compounds \#1-4 at 50 and $200 \mu \mathrm{M}$ concentration in all cell lines, albeit their impact was more pronounced in HT-29 (Table 2). The metabolite accumulation increased dose-dependently, significantly so for compound \#1 in HCT 116 (Figure 10) and \#1-5 in HT-29 cells (Figure 9). In the case of compounds \#2, \#3 and \#5, the maximal stimulatory effect was at $50 \mu \mathrm{M}$ concentration. Noteworthy, the expression ratios at $5 \mu \mathrm{M}$ were indicative of an inhibitory effect on arginine accumulation in HT-29 (Figure 9). Unlike other tested oxicams, $200 \mu \mathrm{M}$ compound \#5 in Caco-2 cells downregulated arginine (Table 2, Figure 8).

Intracellular citrulline concentration increased along with increasing drug concentration in Caco-2 cells, significantly so for compounds \#2-4 (Figure 8). In pairwise analysis, significant citrulline upregulation was observed in Caco-2 cells for $200 \mu \mathrm{M}$ compounds \#1-3 and in HCT 116 cells for $200 \mu \mathrm{M}$ compounds \#2 and \#3 (Table 2).

Ornithine was upregulated by compounds \#1-3 and \#5 at 50 and $200 \mu \mathrm{M}$ concentrations in HCT 116 and HT-29 cells (Table 2), while only $200 \mu \mathrm{M}$ compound \#1 was effective in Caco-2 cells (Table 2), increasing the amino acid concentration in a dose-dependent manner (Figure 8). A significant increase in ornithine accumulation ratio along with increasing drug concentration could be observed also for compounds \#1 and \#4 in HT-29 cells (Figure 9). 
Intracellular ADMA was upregulated by $200 \mu \mathrm{M}$ compounds \#1-3 in Caco-2 and HCT 116 cells and by $50 \mu \mathrm{M}$ in HT-29 cells (Table 2). The accumulation rates in stimulated Caco-2 cells increased dose-dependently for compounds \#1-4 (Figure 8) and in HT-29 cells for compound \#1 (Figure 9).

Likewise, SDMA concentration increased in response to stimulation and the effect was more pronounced than in case of ADMA. It was upregulated by $50 \mu \mathrm{M}$ compounds \#1-3 and \#5 in HCT 116 and HT-29 cells and by $200 \mu \mathrm{M}$ compounds \#1-4 in all cell lines (Table 2). Accumulation ratios increased along with drug concentration, significantly so for compound \#1 in Caco-2 (Figure 8) and \#1 and \#4 in HT-29 cells (Figure 9).

Pairwise analysis showed that compounds \#2 and \#3 in HT-29 cells tended to increase intracellular DMA level (Table 2). However, there was no significant dose-depended effect as there was a great variability in DMA concentration between experiments (Figures 8-10).

In addition, the effect of oxicams at $200 \mu \mathrm{M}$ was analyzed following shorter (6-h) incubation. Compound \#1 increased arginine by 1.8-fold, ADMA by 1.6-fold, and SDMA by 1.8-fold in HT-29 cells. Longer (72-h) stimulation with low $(5 \mu \mathrm{M})$ concentration, analyzed for compounds \#4-5 and classic oxicams had no significant effect in any investigated cell line (Table S2).

\subsubsection{Effect of Oxicam Drugs on Nitrite and Nitrate Concentrations in Conditioned Media}

Gaseous NO has a very short half-life and its more stable metabolites, nitrite $\left(\mathrm{NO}_{2}^{-}\right)$and nitrate $\left(\mathrm{NO}_{3}{ }^{-}\right)$, determined colorimetrically after Griess reaction, are used as an indirect measure of $\mathrm{NO}$ production [32]. Total nitric oxide $\left(\mathrm{NO}_{2}{ }^{-} / \mathrm{NO}_{3}{ }^{-}\right)$was calculated but, with the exception of slightly decreased NO by compound \#1 at $200 \mu \mathrm{M}$ after 6-h stimulation of HCT 116 cells and a similar tendency observed in Caco-2 for compounds \#1 and \#2 at 5 and $50 \mu \mathrm{M}$ after 24-h stimulation, no changes were observed.

\section{Discussion}

Cancer metabolic reprogramming is believed to hold a great potential as a source of novel biomarkers and molecular targets for chemoprevention and treatment [5]. Altered concentration of L-arginine/NO pathway metabolites at systemic level and their utility as diagnostic and prognostic tools in CRC has already been demonstrated [7]. An accumulation of arginine, citrulline, ADMA, and SDMA in colorectal cancer tissue has been shown as well $[10,33,34]$. Here, we intended to unravel the molecular background of these alterations, aiming at a comprehensive analysis going beyond the well-studied NO synthases and arginases, and to evaluate the ability of classic and novel oxicam NSAIDs to modulate the arginine/NO pathway.

As expected, pairwise analysis of matched cancerous and non-cancerous tissue showed significant elevation of NOS2 transcripts in tumors, corroborating earlier reports (reviewed in [35]). The NO generated by NOS2 isoform contributes to the formation of peroxinitrite, assisting in macromolecule damage and genome destabilization and thus facilitating neoplastic transformation [36]. Accordingly, local expression of NOS2 is upregulated in inflammatory bowel conditions [6] and linked with increased risk of CRC development [35]. The NO is also implicated in the promotion of angiogenesis and therefore in aiding cancer cell dissemination [37]. In this respect, targeting NOS2 may be considered beneficial in both chemopreventive and antiangiogenic capacity. In animal models of colon carcinogenesis, piroxicam has been shown to downregulate protein iNOS expression and reduce NO synthesis, determined indirectly by nitrite and nitrate production [38]. Here, solely Caco-2 cells had quantifiable NOS2 expression, which-however-was affected neither by piroxicam nor meloxicam. In turn, novel oxicam drugs stimulated NOS2 expression at a $200 \mu \mathrm{M}$ concentration. However, upregulated NOS2 expression did not translate into accelerated NO synthesis as total NO tended to be reduced following Caco-2 stimulation, probably owing to the concomitant ADMA accumulation. Noteworthy, the dose-dependent responses of Caco-2 cells to oxicam stimulation were frequently opposite to those of HT-29 or HCT 116 and therefore the observation made on Caco-2 should not be easily generalized. 
The ADMA is a natural inhibitor of NO synthases but its role in cancer is severely understudied and equivocal. On one hand, it has been shown to confer protection to colonic cancer cells against nutritional stress and doxorubicin-induced death [39], giving rationale for observed metabolite accumulation in colorectal tumors [33,34]. On the other hand, it interferes with vascular endothelial growth factor (VEGF)-induced angiogenesis. Consequently, targeting DDAH1, its key degrading enzyme, is viewed as an antiangiogenic strategy (reviewed in [37]). However, our analysis of clinical samples showed the downregulation of $D D A H 1$ and $D D A H 2$ in colonic tumors. While consistent with ADMA accumulation [33,34], our observation contradicts the results of RNA-seq expression data analysis, indicating higher DDAH1 expression level in tumors than normal tissue in colonic and rectal adenocarcinomas [37]. Still, in line with the cancer-promoting activities attributed to DDAH1 [40-43] and DDAH2 [44], the expression ratio (tumor-to-adjacent) of DDAH2 tended to increase with cancer advancement, reflecting lymph node involvement. The above-mentioned RNA-seq expression data analysis has revealed cancer type-dependent up- or downregulation of $D D A H s$ expression as well as a lack of consistency between transcriptional patterns of DDAH1 and DDAH2 [37]. Moreover, the data concerning DDAHs' role in cancer are far from equivocal and might also be cancer type-dependent and context-related. As mentioned, DDAH1 is implicated in promoting angiogenesis via the indirect upregulation of NO and VEGF-A [40,45,46]. It has also been shown to affect the Wnt/ $\beta$-catenin pathway and, as such, might be implicated in epithelial-mesenchymal transition (EMT) [47]. However, complicating DDAH1 relevance in cancer, the enzyme depletion and not its upregulation induced EMT in gastric cancer. Moreover, forced DDAH1 overexpression inhibited cell migration and caused degradation of $\beta$-catenin [48]. Furthermore, corroborating our observations in CRC and also opposing the results of RNA-seq expression data analysis, Ye et al. [48] showed DDAH1 downregulation in patient-derived tumor samples, associated with more aggressive phenotype and poor patient survival. Contrary results have been reported for prostate [41] and breast cancers [42], in which DDAH1 was overexpressed in cell lines with aggressive phenotype and its knockout resulted in inhibition of cell migration, implicating the enzyme in breast and pancreatic cancer invasion and metastasis [42,43]. Furthermore, DDAH2 has been shown to promote angiogenesis via upregulating the expression of the endothelial isoform of NOS, as demonstrated in lung adenocarcinoma cell lines, and to be associated with aggressive lung cancer phenotype as well as poor patient survival [44].

Noteworthily, the ADMA and SDMA accumulation has been observed in both tumor and non-cancerous tumor-adjacent tissue [33]. Therefore, we compared the level of enzyme expression in tumors and adjacent tissue to that in normal colonic mucosa. Normal tissue was obtained from patients undergoing polypectomy of benign polyps. The rationale for comparative analysis was that macroscopically normal mucosa surrounding tumor might already be altered at the molecular level, creating a tumor-promoting environment $[29,30]$. Many cases of such changes have been documented in various cancers, including CRC [49-51]. Interestingly, we found that the expression level of DDAHs was comparable between normal mucosa and tumors, while both genes were upregulated in still non-transformed tumor-adjacent tissue. Supporting possible DDAHs involvement in predisposing to cancer development, colonic DDAH1 expression has been upregulated in patients with Crohn's disease, solely during the disease flare, while that of $D D A H 2$ was also upregulated during remission. In patients with ulcerative colitis, only $D D A H 2$ has been upregulated, and exclusively during the disease flare [6].

The $D D A H$ downregulation in tumors, even if not apparent, could not explain reported co-accumulation of SDMA, not catabolized by these enzymes. The ADMA and SDMA pool is regulated by the rate of their catabolism/excretion as well as synthesis, in which a prominent role is played by the PRMTs. While there seem to be no significant differences in PRMT1 and PRMT5 expression between colorectal tumors and adjacent-tissue in pairwise analysis, both genes appeared to be upregulated in CRC patients as compared to normal mucosa. Overexpression of PRMT1 and PRMT5 in both cancerous and non-transformed tissue would explain ADMA and SDMA accumulation reported elsewhere [33,34]. Early death of knockout mice stresses the importance of PRMT1 and PRMT5 
enzymes [52]. Nonetheless, little is known on their status and role in cancer. Recent findings reveal that the significance of PRMT enzymes goes far beyond regulation of NO synthesis, as they seem to play a key role in the global regulation of RNA splicing and translation [53]. They have been reportedly overexpressed in certain cancers [52] and, therefore, the anticancer potential of PRMT inhibitors is currently being investigated [54]. The PRMT1 enzyme depletion has been shown to induce cell cycle arrest and reduce cancer cell proliferation, while an overexpression of one of the PRMT1 variants has been shown to reduce apoptosis (reviewed in [55]). Previously, Mathioudaki et al. [56] evaluated the expression pattern of alternative splicing variants of PRMT1, demonstrating that colon carcinogenesis and CRC aggressiveness is associated with a specific PRMT1 variant, denoted $v 1$. The primer pair used here was not variant-specific and allowed for the amplification of v1-v4 isoforms of PRMT1, thus reflecting rather global PRMT1 expression, which may explain the lack of association with CRC pathological data. The PRMT5 activity has been linked with cell transformation and thus implicated in cancer initiation [57]. Correspondingly, the upregulation of PRMT1 and PRMT5 expression also accompanied bowel inflammation in patients with Crohn's disease and ulcerative colitis [6]. In addition, PRMT5 overexpression has been associated with poor prognosis in gastric, lung, and breast cancers [57]. Only recently, a novel function of PRMT5 has been discovered-the enzyme has been implicated in regulating Hsp90A function as its knockdown results in the degradation of Hsp90A client proteins and cell apoptosis. As Hsp90A is a known cancer-related chaperone, targeting PRMT5 may have additional anticancer benefit in lifting a protection exerted by Hsp90A over a number of oncoproteins [58].

Therefore, it is of potential clinical relevance that the oxicams tested here occurred to inhibit transcription of PRMTs as well as DDAHs. While piroxicam had no significant impact, a substantial and significant effect was observed for $200 \mu \mathrm{M}$ meloxicam, which, however, solely inhibited DDAH2 and exclusively in HT-29 cells. Still, both classic oxicams downregulated DDAHs and PRMTs at protein level, although to lesser degree than novel derivatives. Many experimental, epidemiologic, and clinical studies have suggested that NSAIDs, including oxicams, are promising chemopreventive and anticancer agents [38,59-61]. As mentioned before, not all antitumor activity could be contributed to cyclooxygenase inhibition. Accordingly, the inhibition of JAK3 and STAT3 [38] and c-Myc [60] expression and activity has been implicated in the anti-neoplastic mechanism of piroxicam. However, the intensification of side effects, especially on the gastrointestinal tract, has become an obstacle to perusing piroxicam application in chemoprevention [62,63]. Therefore, Szczęśniak-Sięga et al. [28] obtained new oxicams analogues without gastrotoxicity as potential safer chemopreventive agents. The modifications at the 2-position of the thiazine ring included the replacement of a small methyl substituent with an extended arylpiperazine pharmacophore, because Hatnapure et al. [64] noted that the high electron donating ability of the piperazine moiety can be explicitly correlated to high anti-inflammatory activity of compounds. At the same time, changes in the 3-position of the thiazine involved the replacement of a 2 pyridocarbamoyl substituent with the benzoyl moiety, since it has been shown that such modification increases the analgesic effect [65]. The thiazine and piperazine nitrogen atoms were connected by two types of linker-propylene linker, present in many potent analgesic arylpiperazine derivative, and oxoethylene linker, because of the introduction of a carbonyl moiety to the alkyl linker aimed at intensifying analgesia in accordance with the pharmacophore model proposed by Dogruer et al. [66].

Here, we showed that oxicam analogues were more effective than piroxicam and meloxicam in modulating DDAHs and PRMTs. They inhibited both DDAH1 and DDAH2, and, even more markedly, both PRMT1 and PRMT5 in HT-29 and HCT 116 cells. These novel derivatives differ from classic oxicams with the presence of arylpiperazine moiety, indicating its significance for affecting the transcription of pathway enzymes. The compound \#3 seems to be the most effective and act consistently, in a dose-dependent manner. It inhibited DDAH1 expression in HCT 116 and HT-29 and DDAH2 expression in HT-29 and PRMT1 and PRMT5 in both these cell lines. A dose-dependent effect was also observed in the case of compound \#2 on PRMT1 expression in both HCT 116 and HT-29 and compounds \#2 and \#5 on PRMT1 in HCT 116 and HT-29 or solely HT-29, respectively, or compound \#4 
on PRMT5 in HCT 116 and HT-29 cells. Referring to differences in the compound efficiency of these in chemical structure seems to indicate that the presence of electron-withdrawing substituents (present in compounds \#2-5 but not in \#1) is beneficial for inhibiting enzyme transcription. Compound \#3 is distinguished by the presence of two such substituents, both fluorine atoms and thus stronger in terms of electron-withdrawing compared to the fluorine and chlorine present in compound \#5. In addition, compound \#3 contains a three-carbon linker (propylene) between thiazine and piperazine nitrogens, instead of two-carbon linker with an additional carbonyl group (2-oxoethylene) present in compounds $\# 4$ and \#5, implying its significance for the efficient inhibition of pathway enzyme transcription.

As pointed out by Faubert et al. [4], it becomes increasingly apparent that alterations in metabolic pathways fueling the growth of localized tumors are distinct from those facilitating metastasis and resistance to anticancer treatment. Concerning the L-arginine/NO pathway, studies on mice models of breast cancer have revealed that early metastatic disease is characterized by a shift towards arginase and polyamine synthesis [67]. Intriguingly, novel oxicam analogues, at $200 \mu \mathrm{M}$ concentration, had an even more substantial but stimulatory effect on $A R G 2$ expression. In turn, a low compounds concentration tended to have an opposite effect. It was clearly visible at protein level, where $5 \mu \mathrm{M}$ drug concentrations downregulated arginase-2. Among the tested analogues, compound \#1 upregulated the enzyme expression at both mRNA and protein level more markedly than others. Piroxicam had no effect, while meloxicam displayed an inverse pattern to novel oxicam analogues. It slightly upregulated ARG2 gene expression in HCT 116 and HT-29 cells at a low concentration but downregulated at high. Those observations were confirmed at the protein level in HT-29 cells, where $200 \mu \mathrm{M}$ meloxicam indeed downregulated arginase-2. The enzyme expression in clinical samples was too low to be reliably quantified, although this isoform is thought to be expressed in extrahepatic organs, including intestine. Moreover, Wu at al. [68] analyzed the Cancer RNA-seq Nexus (CRN) public database and found $A R G 2$ to be upregulated in CRC tumors. Functional experiments have shown that silencing $A R G 2$ resulted in the attenuation of HT-29 cell proliferation, migration, and invasion and increased apoptosis. In turn, ARG2 knockout increased the expression of TCR $\zeta$ on co-cultured Jurkat cells [68], implying arginase 2 in promotion of tumor growth and immune evasion. Here, we evaluated the expression of $A R G 1$ and found it to be elevated in both tumors and tumor-adjacent tissue as compared to normal mucosa. Arginase- 1 is considered a hepatic enzyme, expressed also in myeloid cells such as M2 polarized macrophages, dendritic cells, and myeloid-derived suppressor cells (MDSC) [69]. Upregulated arginase 1, leading to the depletion of extracellular arginine, is a hallmark of tumor immunosuppression and an immunomodulatory target in anti-cancer therapy [13,70,71]. In addition, ornithine produced by the enzyme is a key source of tumor-promoting polyamines in proliferating cells $[15,71,72]$. Consistently, arginase activity is reportedly elevated in CRC patients, both in tumor tissue [72] and at systemic level [73], more so in patients with liver metastases [73]. Corroborating our observations, a more recent study has shown arginase 1 upregulation at mRNA and protein level, which was more pronounced at stage III and IV and in tumors accompanied by lymph node metastases. Moreover, the enzyme overexpression was associated with adverse prognoses for overall and disease-free survival [74]. Others have shown that tumors, e.g., in ovarian cancer, can use small extracellular vesicles to deliver the enzyme, as a metabolic checkpoint molecule, to distant immune cells in order to induce immunosuppression [75]. In the present study, ARG1 additionally correlated positively with tumor grade, indicative of its aggressiveness. Taking into account the role of arginases, their upregulation by novel oxicam analogues, observed here, is rather undesirable. However, a protective role of MDSC-derived arginase 1, favoring accumulation of IL-17A and leading to relief of colitis has recently been demonstrated by Ma et al. [76]. Moreover, other NSAIDs, e.g., diclofenac, have been shown to increase protein expression and the activity of arginase 1, which, however, translated into the inhibited growth of xenografted pancreatic tumors. The enzyme probably acted by diminishing arginine availability for NO synthesis and exerted additional anti-angiogenic effects [77].

While ARG2 expression in colonic cell lines was clearly upregulated by novel oxicam analogues at $200 \mu \mathrm{M}$ concentration, further confirmed at the protein level, so was the concentration of arginine. 
This observation is counterintuitive, as arginase metabolizes arginine to produce ornithine, further used for polyamine synthesis. In turn, this time consistently with upregulated $A R G 2$, the intracellular concentration of ornithine was increased as well. Noteworthily, ornithine accumulation may also indicate a block on the level of ornithine decarboxylase (ODC). This possibility warrants further investigation because of the significance of polyamine for tumor growth and resistance to chemotherapy $[11,12,15]$. It is substantiated by the observation that several NSAIDs [78], including piroxicam [61], have been shown to inhibit the enzyme. Moreover, ODC expression is controlled by $c-M y c$ gene [19] and piroxicam has been demonstrated to interfere with its signaling [60].

Arginine was accumulated also in Caco-2 cells, in which $200 \mu \mathrm{M}$ novel oxicam analogues additionally induced expression of NOS2, another arginine-metabolizing enzyme. However, the stimulatory effect on arginine conversion to $\mathrm{NO}$ might be, at least to some degree, counteracted by concomitant elevation in ADMA. The ADMA would inhibit NOS enzymatic activity, preserving arginine. The notion is supported by the lack of elevation in nitrites and nitrates despite NOS2 upregulation.

It is possible that investigated oxicam analogues influence the expression of amino acid membrane transporters, leading to arginine accumulation, despite the upregulated expression of ARG2 and NOS2. The notion is supported by the accumulation of both dimethylarginines and citrulline, which is also counterintuitive. The evaluated oxicam analogues inhibited DDAHs, which would potentially lead to ADMA accumulation. However, the effect was observed primarily in HT-29 cells, while ADMA accumulation was observed rather in Caco-2 line and accompanied by an elevation in citrulline, a product of DDAHs. Moreover, the downregulation of PRMT expression would lead to diminished ADMA and SDMA generation, unless they were prevented from being released from the cell. It is worth mentioning, that although the effects of SDMA are mostly unknown, its accumulation in colorectal tumors has been linked with increased risk of metastasis [33] and therefore is not beneficial. There are many arginine transporters, several of which mediate both influx and efflux [79] and can transport arginine as well as its methylated derivatives. Importantly, their expression might be upregulated by classic pro-inflammatory cytokines such as IL-1 $\beta$ and TNF $\alpha$, with CAT- 1 and CAT-2B being an example [79]. Therefore, oxicam analogues, by virtue of being anti-inflammatory agents, may indirectly decrease transporter expression, leading to diminished metabolite efflux.

\section{Materials and Methods}

\subsection{Patients}

Paired bowel samples, including tumor and tumor-adjacent tissues (macroscopically normal), were harvested from 55 patients undergoing curative resection of histologically confirmed colorectal adenocarcinoma in the Regional Specialist Hospital in Wroclaw in Department of Oncological Surgery, between 2013 and 2015. Preoperative workup consisted of bloodwork, colonoscopy, and computed tomography (abdominal and pelvic) and-for rectal cancer-pelvic magnetic resonance imaging. The 7th edition of TNM cancer grading system was used for pathological staging. Patients' characteristics are given in Table 3.

Harvested samples were washed with phosphate buffered saline (PBS) and immersed in RNAlater solution (Ambion Inc., Austin, TX, USA). Samples were kept at $-80{ }^{\circ} \mathrm{C}$ until RNA isolation.

For comparative purposes, we retrieved previously collected data [6] on enzyme expression in normal large bowel mucosa from patients submitted for polypectomy of benign polyps $(n=20)$. 
Table 3. Patients' characteristics.

\begin{tabular}{cc}
\hline Parameter & CRC \\
\hline N & 55 \\
Sex (F/M), n & $22 / 33$ \\
Age [yrs.], median (range) & $68(28-84)$ \\
Stage (0/I/II/III/IV) & $8 / 6 / 14 / 23 / 4$ \\
Primary tumor, T (Tis/1/2/3/4) & $8 / 2 / 7 / 30 / 8$ \\
Lymph node metastasis, N (0/1/2) & $28 / 14 / 13$ \\
Distant metastasis, M (no/yes) & $51 / 4$ \\
Grade, G (1/2/3/x) & $8 / 36 / 7 / 4$ \\
Tumor location (left-side/right-side/rectum) & $17 / 17 / 21$
\end{tabular}

$\mathrm{N}$, number of patients; F/M, female-to-male ratio; CRC, colorectal cancer; yrs., years; TNM, tumor-node-metastasis cancer staging system; T, depth of tumor invasion; Tis, tumor in situ; N, lymph node metastasis; M, distant metastasis; $\mathrm{G}$, histological grade.

\subsection{Ethical Approval}

Sample collection for the study purpose was approved by the Medical Ethics Committees of Regional Specialist Hospital (\#KB/nr 1/rok 2012 from 26 June 2012).

\subsection{Cell Cultures}

Human colon cancer cell lines: HT-29 (ATCC ${ }^{\circledR}$ HTB-38 ${ }^{\mathrm{TM}}$ ), HCT 116 (ATCC ${ }^{\circledR}$ CCL-247 ${ }^{\mathrm{TM}}$ ), and Caco-2 (ATCC ${ }^{\circledR}$ HTB-37 ${ }^{\mathrm{TM}}$ ) were obtained from ATCC (MD, USA). Cells were cultured in CELCULTURE ${ }^{\circledR}$ CCL-170B-8 incubator (Esco, Singapore) at $37^{\circ} \mathrm{C}$ in $95 \%$ air with $5 \% \mathrm{CO}_{2}$ in $75 \mathrm{~cm}^{2}$ cell culture flasks (Thermo Fisher Scientific, Waltham, MA, USA). Dulbecco's modified Eagle medium (Gibco, Thermo Fisher Scientific) with 10\% fetal bovine serum (Gibco) and 1\% GlutaMAX ${ }^{\text {TM}}-\mathrm{I}$ (Gibco) was used with addition of stabilized 1\% antibiotic antimycotic solution containing 10,000 units of penicilin/mL, $10 \mathrm{mg} / \mathrm{mL}$ of streptomycin, $25 \mu \mathrm{g} / \mathrm{mL}$ of amphotericin B (Sigma-Aldrich, St. Luis, MO, USA). Medium was replaced with fresh one every third day. Upon growth termination, cells were washed with Dulbecco's phosphate buffered saline (Gibco) and harvested using TrypLE ${ }^{\text {TM }}$ Express (Gibco). Collected cells were stained with $0.4 \%$ trypan blue solution (Invitrogen, Thermo Fisher Scientific) and quantified using Countess ${ }^{\mathrm{TM}}$ Automated Cell Counter (Invitrogen).

Cells were seeded at $2 \times 10^{5}$ cells/well on a 6-well plate for transcriptomic, metabolomic, and protein analysis. For specified times (6, 24, 72, and/or 48 h), cells were treated with piroxicam (Sigma-Aldrich), meloxicam (Alfa Aesar, Thermo Fisher Scientific), or novel analogues of oxicam dissolved in dimethyl sulfoxide (DMSO) at 5, 50, or $200 \mu \mathrm{M}$ concentration. Cells treated with solvent alone (DMSO, up-to $0.25 \%$ ) were used as controls and referred to as "untreated cells". Compound \#1 at $200 \mu \mathrm{M}$ was dissolved in $1 \%$ DMSO due to its lower solubility. Cells treated with $1 \%$ DMSO were used as respective control.

For transcriptomic analysis, after the 6, 24 and $72 \mathrm{~h}$ media were removed and cells were lyzed using Trizol (Thermo-Fisher Scientific). Collected lysates were stored at $-80^{\circ} \mathrm{C}$.

For metabolomic analysis, after the 6, 24 and $72 \mathrm{~h}$ media were removed and cells were washed twice with PBS and subjected to methanol extraction (cold methanol:water (3:1), repeated twice). Methanol extracts were then collected and stored at $-80{ }^{\circ} \mathrm{C}$ until LC-MS/MS analysis. Following extraction, cells fixed on plates with methanol were used to determine protein content (surrogate for cell density) with sulforhodamine B (SRB) assay.

For protein determination, after the $48 \mathrm{~h}$ medium was discarded and cells were mechanically detached after addition of phosphate buffered saline (PBS) with protease inhibitor cocktail (Complete Tablets EDTA-free; Roche Diagnostics, Mannheim, Germany). Obtained cell suspensions were kept frozen at $-80^{\circ} \mathrm{C}$ until analysis. 


\subsection{Synthesis of the Novel Oxicam Drugs}

Synthesis and experimental data of studied compounds \#1-5 were previously reported [80-82]. Briefly, the starting material for the synthesis of the above-mentioned compounds was commercially available 1,1-dioxo-1,2-benzothiazol-3-one (saccharin). It was condensed with 2-bromoacetophenone (for compound \#1) or 2-bromo-4'-fluoroacetophenone (for compounds \#2, \#3 and \#4) or 2-bromo-4'-chloroacetophenone (for compound \#5) in dimethylformamide (DMF) in the presence of triethylamine (TEA). The condensation products obtained were then rearranged to the corresponding 1,2-benzothiazine ring in Gabriel-Colman rearrangement. The final compounds were prepared by alkylation of corresponding 1,2-benzothiazine with 1-(3-chloropropyl)-4-phenylpiperazine (for compound \#1 and \#2) or 1-(3-chloropropyl)-4-(2-fluorophenyl)piperazine (for compound \#3) or 1-(2-chloroacetyl)-4-(2-fluorophenyl)piperazine (for compounds \#4 and \#5) giving five new compounds. The separated products were purified by the crystallization from ethanol. The structures of the compounds obtained were confirmed by elemental and spectral analyses (MS, FTIR, 1H NMR, 13C NMR). Piroxicam (Sigma-Aldrich) and meloxicam (Alfa Aesar) as reference standards were obtained from commercial sources.

\subsection{Analytical Methods}

\subsubsection{Transcriptomic Analysis}

\section{RNA Extraction and Purification}

Tissue fragments of 30-40 mg were homogenized in lysis buffer with 2-mercaptoethanol (100:1) (Sigma-Aldrich) using Fastprep 24 Homogenizer (MP Biomedical, Solon, OH, USA).

Phenol-chloroform extraction was used for RNA isolation. Crude RNA was further purified using PureLink ${ }^{\mathrm{TM}}$ RNA Mini Kit (Invitrogen). On-column removal of genomic DNA with DNase (PureLink ${ }^{\mathrm{TM}}$ DNase Set, Invitrogen) was applied. Isolated RNA was quantified spectrophotometrically using NanoDrop 2000 from Thermo-Fisher Scientific. The purity of RNA isolates was determined as absorbance ratios of $260 / 280 \mathrm{~nm}$ and $260 / 230 \mathrm{~nm}$. In turn, RNA integrity was evaluated using the LabChip microfluidic technology on Experion platform, using dedicated Experion RNA StdSens analysis kits (BioRad, Herkules, CA, USA).

\section{Reverse Transcription}

RNA, $500 \mathrm{ng}$ (clinical samples) or $1000 \mathrm{ng}$ (cell culture samples) per $20 \mu \mathrm{L}$ of reaction mixture, was transcribed into cDNA using C1000 termocycler (BioRad) and iScript ${ }^{\mathrm{TM}} \mathrm{cDNA}$ Synthesis Kit (BioRad) following suggested protocol.

\section{Real-Time (Quantitative) PCR}

qPCRs were conducted using SsoFast EvaGreen ${ }^{\circledR}$ Supermix (BioRad) on CFX96 Real-Time PCR thermocycler (BioRad). The following cycling conditions were applied: activation at $95^{\circ} \mathrm{C}$ for $30 \mathrm{~s}$, denaturation at $95^{\circ} \mathrm{C}$ for $5 \mathrm{~s}$, annealing/extension at $61^{\circ} \mathrm{C}$ for $5 \mathrm{~s} ; 45$ cycles, followed by melting curve analysis $\left(60-95^{\circ} \mathrm{C}\right.$ with fluorescent reading every $\left.0.5^{\circ} \mathrm{C}\right)$. The reaction mixture consisted of cDNA $\left(2 \mu \mathrm{L}\right.$; diluted 1:5), $2 \times$ SsoFast EvaGreen ${ }^{\circledR}$ Supermix $(10 \mu \mathrm{L}), 10 \mathrm{nM}$ forward and reverse target-specific primers $(1 \mu \mathrm{L}$ of each), and water up to $20 \mu \mathrm{L}$. Primers were synthesized by Genomed (Warsaw, Poland) and their characteristics is given in Table 4. 
Table 4. Characteristics of applied primers.

\begin{tabular}{|c|c|c|c|c|}
\hline Gene Symbol & Full Name & Accession No. & Sequence $5^{\prime} \rightarrow 3^{\prime}$ & Size $[b p]$ \\
\hline PPIA $^{1}$ & Peptidylprolyl isomerase A & NM_021130.3 & $\begin{array}{l}\text { F: ggcaaatgctggacccaacaca } \\
\text { R: tgctggtcttgccattcctgga }\end{array}$ & 161 \\
\hline$R P L P 0^{1}$ & Ribosomal protein, large, P0 & NM_001002.3 & $\begin{array}{l}\text { F: tcacaacaagcataccaagaagc } \\
\text { R: gtatccgatgtccacaatgtcaag }\end{array}$ & 263 \\
\hline$A R G 1^{2}$ & Arginase-1 & NM_001244438.2 & $\begin{array}{l}\text { F: tcatctgggtggatgctcacac } \\
\text { R: gagaatcctggcacatcgggaa }\end{array}$ & 130 \\
\hline$A R G 2^{1}$ & Arginase-2 & NM_001172.4 & $\begin{array}{l}\text { F: ctggcttgatgaaaaggctctcc } \\
\text { R: tgagcgtggattcactatcaggt }\end{array}$ & 119 \\
\hline NOS $2^{1}$ & $\begin{array}{l}\text { Inducible nitric oxide } \\
\text { synthase }\end{array}$ & NM_000625.4 & $\begin{array}{l}\text { F: gctctacacctccaatgtgacc } \\
\text { R: ctgccgagatttgagcctcatg }\end{array}$ & 136 \\
\hline PRMT1 $^{1}$ & $\begin{array}{c}\text { Arginine } \\
N \text {-methyltransferase- } 1\end{array}$ & NM_001536.5 & $\begin{array}{l}\text { F: tgcggtgaagatcgtcaaagcc } \\
\text { R: ggactcgtagaagaggcagtag }\end{array}$ & 142 \\
\hline PRMT5 ${ }^{1}$ & $\begin{array}{c}\text { Arginine } \\
N \text {-methyltransferase-5 }\end{array}$ & NM_006109.5 & $\begin{array}{l}\text { F: ctagaccgagtaccagaagagg } \\
\text { R: cagcatacagctttatccgccg }\end{array}$ & 136 \\
\hline$D D A H 1^{1}$ & $\begin{array}{c}\text { Dimethylarginine } \\
\text { dimethylaminohydrolase-1 }\end{array}$ & NM_012137.4 & $\begin{array}{l}\text { F: atgcagtctccacagtgccagt } \\
\text { R: ttgtcgtagcggtggtcactca }\end{array}$ & 151 \\
\hline$D D A H 2^{1}$ & $\begin{array}{c}\text { Dimethylarginine } \\
\text { dimethylaminohydrolase-2 }\end{array}$ & NM_001303007.2 & $\begin{array}{l}\text { F: ctttcttcgtcctgggttgcct } \\
\text { R: ctccagttctgagcaggacaca }\end{array}$ & 136 \\
\hline$G A P D H^{2}$ & $\begin{array}{c}\text { Glyceraldehyde-3-phosphate } \\
\text { dehydrogenase }\end{array}$ & NM_001256799.3 & $\begin{array}{l}\text { F: tagattattctctgatttggtcgtattgg } \\
\text { R: gctcctggaagatggtgatgg }\end{array}$ & 223 \\
\hline
\end{tabular}

1 , Sequences designed by Origene (www.origene.com); ${ }^{2}$, sequences designed with Beacon Designer Probe/Primer Design Software (BioRad). All sequences were validated in silico (Blast analysis), and their specificity confirmed in melting curve analysis and agarose electrophoresis. F, forward primer; R, reverse primer.

\section{Normalization Strategy}

Prior to analysis, technical replicates were averaged. For each sample set investigated, a geometric mean of all $\mathrm{Cq}$ values was calculated. It was subtracted from individual sample $\mathrm{Cq}$, yielding $\triangle \mathrm{Cq}$, subsequently linearized by $2^{\wedge} \triangle \mathrm{Cq}$ transformation, and normalized using geometric mean of PPIA and RPLPO for clinical samples [83] or expression of GAPDH for cell culture experiments. The obtained "normalized relative quantity" (NRQ) values [84] were then subjected to statistical analysis.

\subsubsection{Liquid Chromatography Coupled with Tandem Mass Spectrometry (LC-MS/MS)}

Metabolite concentration in cell cultures was quantified using a method recently developed [85] and routinely used in our laboratory $[6,7,86-88]$ with small modifications.

\section{Sample Preparation}

Samples were dried using centrifugal vacuum concentrator (HETOVAC) at $50{ }^{\circ} \mathrm{C}$ and then re-dissolved in $10 \mu \mathrm{L}$ of borate buffer $\left(\mathrm{pH}=9.2\right.$ ), consisting of $0.025 \mathrm{M} \mathrm{Na}_{2} \mathrm{~B}_{4} \mathrm{O}_{7} \times 10 \mathrm{H}_{2} \mathrm{O}$ with $1.77 \mathrm{mM} \mathrm{NaOH}$ and $10 \mu \mathrm{L}$ of internal standard solution $(7 \mu \mathrm{M}$ D6-ornithine, $10 \mu \mathrm{M}$ D7-arginine, $0.1 \mu \mathrm{M}$ D7-ADMA, $2 \mu \mathrm{M}$ D4-cytrulline and $0.25 \mu \mathrm{M}$ D6-DMA). After mixing for $1 \mathrm{~min}$ at $1200 \mathrm{rpm}$ in $25^{\circ} \mathrm{C}$, $20 \mu \mathrm{L}$ of acetonitrile with $10 \mu \mathrm{L}$ of $10 \%$ benzoyl chloride in acetonitrile was added and mixed again. Aliquots $(50 \mu \mathrm{L})$ were transferred into chromatographic glass vials with $0.2 \mathrm{~mL}$ borosilicate glass insert.

\section{Chromatographic and Mass Spectrometry Analysis}

Chromatographic analysis was performed using Acquity UPLC system (Waters, Milford, MA, USA). Sample temperature was set at $5{ }^{\circ} \mathrm{C}$ and column temperature at $60{ }^{\circ} \mathrm{C}$. Samples $(2 \mu \mathrm{L})$ were injected onto the Waters HSS T3 column $(1.8 \mu \mathrm{M}, 1.0 \times 50 \mathrm{~mm})$. The flow rate was $0.220 \mathrm{~mL} / \mathrm{min}$ and a total run time was $8.50 \mathrm{~min}$. The following gradient was used: $0.0 \mathrm{~min}-5 \% \mathrm{~B}$ hold for $1 \mathrm{~min}$, $3.5 \mathrm{~min}-14 \% \mathrm{~B}, 5.0 \mathrm{~min}-60 \% \mathrm{~B}, 5.5 \mathrm{~min}-90 \% \mathrm{~B}$ hold for $1.1 \mathrm{~min}, 6.60 \mathrm{~min}-5 \% \mathrm{~B}$, where eluent A was water with $0.1 \%$ formic acid (FA) and eluent $B$ was methanol with $0.1 \%$ FA.

Measurements were performed using Xevo G2 Q-TOF MS (Waters, Milford, MA, USA) with electrospray ionization (ESI) in positive ionization mode. The spray voltage, source temperature, and the desolvation temperature were set at $0.5 \mathrm{kV}, 120^{\circ} \mathrm{C}$ and $400{ }^{\circ} \mathrm{C}$, respectively. Data were acquired using MassLynx software (Waters) for the following ions (m/z): 237.1239 (for ornithine), 
243.1339 (for D6-ornithine), 279.1457 (for arginine), 286.1897 (for D7-arginine), 307.1770 (for ADMA and SDMA), 314.2209 (for D7-ADMA), 263.1090 (for citrulline), 267.1382 (for D4-cytrulline), 150.0919 (for DMA), and 156.1295 (D6-DMA). The following concentration ranges were prepared for standard calibration curves: $0.3-15 \mu \mathrm{M}$ for ornithine, $0.5-25 \mu \mathrm{M}$ for arginine, $0.005-0.25 \mu \mathrm{M}$ for ADMA and SDMA, 0.1-5 $\mu \mathrm{M}$ for citrulline, and 0.014-0.7 $\mu \mathrm{M}$ for DMA.

Obtained metabolite concentrations were then normalized to cell density determined indirectly using the SRB assay.

\section{Sulforhodamine B (SRB) Assay}

The SRB assay allows for determining protein content, proportional to cell number. It was used to normalize the metabolomic results.

Solution of $0.04 \%$ SRB in $1 \%$ acetic acid (Sigma-Aldrich) was added to fixed cells and let stand for $30 \mathrm{~min}$. Subsequently, the unbound dye was removed using 1\% acetic acid. The protein-bound SRB was in turn solubilized by $10 \mathrm{mM}$ Tris base solution $(\mathrm{pH}=10.5)$. The absorbance, proportional to protein content, was measured using an Infinite M200 plate spectrophotometer (Tecan Group Ltd., Männedorf, Switzerland) at $\lambda=492 \mathrm{~nm}$ or $520 \mathrm{~nm}$.

\subsubsection{Nitrate/Nitrite Determination}

Nitrate/nitrite concentration as a surrogate for $\mathrm{NO}$ production was determined in conditioned media using Total Nitric Oxide and Nitrate/Nitrite assay (R\&D Systems, Minneapolis, MN, USA) according to manufacturer's instruction. Obtained concentrations of total and endogenous nitrite and nitrate were normalized to protein concentration in the media. Protein concentration was determined colorimetrically at $\lambda=595 \mathrm{~nm}$ (Infinite M200 plate spectrophotometer) using Bradford method against bovine serum albumin as a standard (Sigma).

\subsubsection{Determination of Protein Expression}

Cell suspensions were thawed and sonicated on ice using the ultrasonic processor UP 200 (Hielscher Ultrasound Technology, Teltow, Germany), during two 30 sec cycles with amplitude set at $40 \%$. To remove non-lysed cells, the suspension was centrifuged $\left(12,500 \times g, 4{ }^{\circ} \mathrm{C}, 10 \mathrm{~min}\right.$.). Total protein concentration was measured colorimetrically at $\lambda=562$ (EnSpire Multimode Plate Reader, PerkinElmer, Waltham, MA, USA) in the supernatants using the bicinchoninic acid (Thermo Fisher Scientific, Walthan, MA, USA) assay [89]. Protein samples $(10 \mu \mathrm{g})$ were diluted 1:1 with $2 \times$ Laemmli sample buffer (Bio-Rad, Hercules, CA, USA) containing 5\% 2-mercaptoethanol, denatured ( $5 \mathrm{~min}$ at $95^{\circ} \mathrm{C}$ ), and resolved by SDS-PAGE electrophoresis [90]. Gels $(0.75 \mathrm{~mm}, 4 \%$ stacking gel and a $10 \%$ resolving gel) were run using Mini-Protean Tetra Cell (Bio-Rad) at constant voltage $200 \mathrm{~V}$ until the dye front reached the bottom of the gel. Subsequently, the separated proteins were transferred (30 min at constant voltage of $25 \mathrm{~V}$ ) to the Immobilon P membrane (Merck-Millipore, Burlington, MA, USA). Dedicated transfer buffer (25 mM Tris, $190 \mathrm{mM}$ glycine, 20\% methanol) and Trans-Blot Turbo transfer system (Bio-Rad) were used. After the transfer, membranes were stained for total protein content using No-Stain ${ }^{\mathrm{TM}}$ Protein Labeling Reagent (Invitrogen, Carlsbad, CA, USA), according to manufacturer's instructions. Then membranes were blocked with 1\% casein blocking buffer (Sigma-Aldrich, Saint Louis, MO, USA) at room temperature for $1 \mathrm{~h}$. After washing, the membranes were incubated (overnight, at $4{ }^{\circ} \mathrm{C}$ ) with specific primary antibodies (Cusabio, Houston, TX, USA). The following dilutions were applied: arginase-2 (1:1000; cat. no. CSB-PA002006GA01HU), DDAH1 (1:1000; cat. no. CSB-PA877002), DDAH2 (1:5000; cat. no. CSB-PA006580LA01HU), PRMT5 (1:1000; cat. no. CSB-PA018734GA01HU), and PRMT1 (1:80; R\&D Systems, Minneapolis, MN, USA; cat. No. AF6016). Antibodies were diluted in PBS-T buffer pH 7.3 (VWR, International, Radmor, PA, USA) with 0.05\% Tween-20 (Thermo Fisher Scientific, Walthan, MA, USA). Unbound antibodies were removed by washing (3 times, 5 min) with PBS-T buffer. Then, the membranes were incubated with HRP-conjugated goat anti-rabbit antibodies (Invitrogen, Carlsbad, CA, USA; cat. no. A27036), diluted 1:50,000, or rabbit anti-goat antibodies 
(Sigma-Aldrich, Sain Louis, Mo, USA; cat. no. A5420), diluted 1:25,000. The analyzed proteins were visualized using Clarity Western ECL chemiluminescent substrate (Bio-Rad) and ChemiDoc MP Imaging System (Bio-Rad). The obtained Western-blot membrane images were analyzed using Image Lab software version 6.0.1 build 34 (Bio-Rad). The chemiluminescence intensity was normalized to the total protein intensity recorded for individual lanes.

\subsection{Statistical Analysis}

Normality of data distribution was tested using Kolmogorov-Smirnov test and homogeneity of variances using Levene test. Paired samples were examined using t-test for paired samples, on log-transformed data, if necessary. Independent samples were analyzed with t-test for independent samples or Mann-Whitney U test for two-group comparisons. One-way analysis of variance (ANOVA), with Tukey-Kramer post-hoc test, or Kruskal-Wallis H-test, with Conover post-hoc test, were applied for multi-group comparisons. Data are reported as means or medians with $95 \%$ confidence interval (CI). Spearman rank correlation test $(\rho)$ was used to assess the association with cancer pathology. All applied tests were two-sided. $p$ values $<0.05$ were considered statistically significant. MedCalc Statistical Software version 19.4.0 (MedCalc Software Ltd., Ostend, Belgium; https://www.medcalc.org; 2020) was used for all analyses.

\section{Conclusions}

Metabolic reprogramming in CRC regarding L-arginine/NO pathway includes overexpression of dimethylarginine dimethylaminohydrolases $(D D A H 1$ and $D D A H 2)$ and protein methyltransferases (PRMT1 and PRMT5), in addition to ARG1 and NOS2. Importantly, transcriptional pattern of the pathway enzymes is altered not only in tumors, but also, or even only, in non-transformed tumor-adjacent tissue, contributing to the phenomenon of tumor molecular margin.

Novel oxicam analogues with reduced gastrotoxicity, differing from piroxicam and meloxicam with arylpiperazine moiety at the thiazine ring, are able to downregulate DDAHs and PRMTs, while classic oxicams had either weak or no effect on their expression. The presence of propylene linker between thiazine and piperazine nitrogens and two fluorine substituents, at arylpiperazine and benzoyl moieties, characterizes the most effective inhibitor of DDAHs and PRMTs expression. In addition to beneficial downregulation of DDAHs and PRMTs and ADMA accumulation, novel oxicam analogues upregulated $A R G 2$ expression and led to the potentially disadvantageous accumulation of arginine and SDMA. Further studies are needed to unravel the mechanisms by which novel oxicam analogues affect L-arginine/NO pathway. Those should include cell lines with varying and determined stage of carcinogenesis and encompass evaluation of analogues' effect on amino acid transporters and other pathway enzymes.

Supplementary Materials: The following are available online at http://www.mdpi.com/2072-6694/12/9/2594/s1, Figure S1: Structures of classic and new oxicam analogues, Figure S2: Pairwise (patient-matched) analysis of expression of arginine/nitric oxide pathway enzymes in patients with colorectal adenocarcinoma, Figure S3: Fold-change in expression of arginine/nitric oxide pathway enzymes in patients with colorectal adenocarcinomas in relation to cancer pathological features, Figure S4: Impact of oxicams on Caco-2 cell viability determined with sulforhodamine B assay, Figure S5: Impact of oxicams on HCT 116 cell viability determined with sulforhodamine B assay, Figure S6: Impact of oxicams on HT-29 cell viability determined with sulforhodamine B assay, Table S1: Effect of novel oxicam analogues on L-arginine/nitric oxide pathway enzymes, Figure S7: Western Blot analysis of protein expression level of ARG2, DDAH1, DDAH2, PRMT1, PRMT5 in HT-29.

Author Contributions: Conceptualization, M.K.-K., B.S.-S., J.W. and I.B.-M.; methodology, M.K.-K., M.G.F., J.W. and I.B.-M.; formal analysis, M.K.-K., B.S.-S., I.S., P.F., M.Z.; M.M.-P., M.G.F., P.S., K.N., R.K. and I.B.-M.; investigation, M.K.-K., I.S., P.F., A.K., M.M.-P., M.G.F., Ł.L., P.S., N.J. and I.B.-M.; resources, M.K.-K., B.S.-S., K.N., R.K. and W.W.; data curation, M.Z., K.N., R.K. and W.W.; writing-original draft preparation, M.K.-K. and B.S.-S.; writing-review and editing, M.K.-K., B.S.-S., I.S. and K.N.; visualization, M.K.-K., B.S.-S., P.F. and P.S.; supervision, M.K.-K.; project administration, M.K.-K., W.W. and I.B.-M.; funding acquisition, M.K.-K., K.N., R.K., W.W. All authors have read and agreed to the published version of the manuscript. 
Funding: This publication was prepared under the project financed from the founds granted by the Ministry of Science and Higher education in the Regional Initiative of Excellence" program for the years 2019-2022, project number 016/RID/2018/19, the amount of funding 11998121.30 PLN. Patients enrollment was supported by the Project, WroVasc-Integrated Cardiovascular Centre", co-financed by the European Regional Development Fund, within Innovative Economy Operational Program, 2007-2013 realized in Regional Specialist Hospital, Research and Development Center in Wroclaw "European Funds-for the development of innovative economy".

Acknowledgments: The authors would like to thank the Foundation of Wroclaw Medical University (FUM) and its Board Chairmen for financing a lease of BioRad Experion platform and CFX96 Real-Time PCR system.

Conflicts of Interest: The authors declare no conflict of interest.

\section{References}

1. Bray, F.; Ferlay, J.; Soerjomataram, I.; Siegel, R.L.; Torre, L.A.; Jemal, A. Global cancer statistics 2018 : GLOBOCAN estimates of incidence and mortality worldwide for 36 cancers in 185 countries. CA Cancer J. Clin. 2018, 68, 394-424. [CrossRef] [PubMed]

2. Alves Martins, B.A.; de Bulhões, G.F.; Cavalcanti, I.N.; Martins, M.M.; de Oliveira, P.G.; Martins, A.M.A. Biomarkers in Colorectal Cancer: The Role of Translational Proteomics Research. Front. Oncol. 2019, 9, 1284. [CrossRef] [PubMed]

3. Hanahan, D.; Weinberg, R.A. Hallmarks of cancer: The next generation. Cell 2011, 144, 646-674. [CrossRef] [PubMed]

4. Faubert, B.; Solmonson, A.; DeBerardinis, R.J. Metabolic reprogramming and cancer progression. Science 2020, 368, eaaw5473. [CrossRef] [PubMed]

5. Torresano, L.; Nuevo-Tapioles, C.; Santacatterina, F.; Cuezva, J.M. Metabolic reprogramming and disease progression in cancer patients. Biochim. Biophys. Acta Mol. Basis Dis. 2020, 1866, 165721. [CrossRef] [PubMed]

6. Krzystek-Korpacka, M.; Fleszar, M.G.; Bednarz-Misa, I.; Lewandowski, Ł.; Szczuka, I.; Kempiński, R.; Neubauer, K. Transcriptional and metabolomic analysis of L-arginine/nitric oxide pathway in inflammatory bowel disease and its association with local inflammatory and angiogenic response: Preliminary findings. Int. J. Mol. Sci. 2020, 21, 1641. [CrossRef] [PubMed]

7. Bednarz-Misa, I.; Fleszar, M.G.; Zawadzki, M.; Kapturkiewicz, B.; Kubiak, A.; Neubauer, K.; Witkiewicz, W.; Krzystek-Korpacka, M. L-Arginine/NO Pathway Metabolites in Colorectal Cancer: Relevance as Disease Biomarkers and Predictors of Adverse Clinical Outcomes Following Surgery. J. Clin. Med. 2020, 9, 1782. [CrossRef]

8. Albaugh, V.L.; Pinzon-Guzman, C.; Barbul, A. Arginine Metabolism and Cancer. Surg. Oncol. 2017, 115, 273-280. [CrossRef]

9. Keshet, R.; Erez, A. Arginine and the metabolic regulation of nitric oxide synthesis in cancer. Dis. Model. Mech. 2018, 11, dmm033332. [CrossRef]

10. Lu, Y.; Wang, W.; Wang, J.; Yang, C.; Mao, H.; Fu, X.; Wu, Y.; Cai, J.; Han, J.; Xu, Z.; et al. Overexpression of arginine transporter CAT-1 is associated with accumulation of L-arginine and cell growth in human colorectal cancer tissue. PLoS ONE 2013, 8, e73866. [CrossRef]

11. Paz, E.A.; LaFleur, B.; Gerner, E.W. Polyamines are oncometabolites that regulate the LIN28/let-7 pathway in colorectal cancer cells. Mol. Carcinog. 2014, 53 (Suppl. 1), E96-E106. [CrossRef]

12. Poisson, L.M.; Munkarah, A.; Madi, H.; Datta, I.; Hensley-Alford, S.; Tebbe, C.; Buekers, T.; Giri, S.; Rattan, R. A metabolomic approach to identifying platinum resistance in ovarian cancer. J. Ovarian Res. 2015, 8, 13. [CrossRef] [PubMed]

13. Szefel, J.; Danielak, A.; Kruszewski, W.J. Metabolic pathways of L-arginine and therapeutic consequences in tumors. Adv. Med. Sci. 2019, 64, 104-110. [CrossRef] [PubMed]

14. Zou, S.; Wanga, X.; Liua, P.; Kea, C.; Xu, S. Arginine metabolism and deprivation in cancer therapy. Biomed. Pharmacother. 2019, 118, 109210. [CrossRef]

15. LoGiudice, N.; Le, L.; Abuan, I.; Leizorek, Y.; Roberts, S.C. Alpha-difluoromethylornithine, an irreversible inhibitor of polyamine biosynthesis, as a therapeutic strategy against hyperproliferative and infectious diseases. Med. Sci. 2018, 6, 12. [CrossRef] [PubMed] 
16. Meyskens, F.L., Jr.; McLaren, C.E.; Pelot, D.; Fujikawa-Brooks, S.; Carpenter, P.M.; Hawk, E.; Kelloff, G.; Lawson, M.J.; Kidao, J.; McCracken, J.; et al. Difluoromethylornithine plus sulindac for the prevention of sporadic colorectal adenomas: A randomized placebo-controlled, double-blind trial. Cancer Prev. Res. 2008, 1, 32-38. [CrossRef] [PubMed]

17. Burke, C.A.; Dekker, E.; Samadder, N.J.; Stoffel, E.; Cohen, A. Efficacy and safety of eflornithine (CPP-1X)/sulindac combination therapy versus each as monotherapy in patients with familial adenomatous polyposis (FAP): Design and rationale of a randomized, double-blind, Phase III trial. BMC Gastroenterol. 2016, 16, 87. [CrossRef]

18. Gurpinar, E.; Grizzle, W.E.; Piazza, G.A. COX-Independent Mechanisms of Cancer Chemoprevention by Anti-Inflammatory Drugs. Front. Oncol. 2013, 3, 181. [CrossRef]

19. Gerner, E.W.; Bruckheimer, E.; Cohen, A. Cancer pharmacoprevention: Targeting polyamine metabolism to manage risk factors for colon cancer. J. Biol. Chem. 2018, 293, 18770-18778. [CrossRef]

20. Obach, R.S.; Lombardo, F.; Waters, N.J. Trend Analysis of a Database of Intravenous Pharmacokinetic Parameters in Humans for 670 Drug Compounds. Drug Metab. Dispos. 2008, 36, 1385-1405. [CrossRef]

21. Ding, H.; Han, C.; Gibson-D'Ambrosio, R.; Steele, V.E.; D'Ambrosio, S.M. Piroxicam selectively inhibits the growth of premalignant and malignant human oral cell lines by limiting their progression through the $S$ phase and reducing the levels of cyclins and AP-1. Int. J. Cancer 2003, 107, 830-836. [CrossRef]

22. Khodaie, F.; Khazaei-Poul, Y.; Moini-Zanjani, T. Anti-proliferative effects of piroxicam and nimesulide on A431 human squamous carcinoma cell line. Int. J. Cancer Manag. 2017, 10, e7565. [CrossRef]

23. Goldman, A.P.; Williams, C.S.; Sheng, H.; Lamps, L.W.; Williams, V.P.; Pairet, M.; Morrow, J.D.; DuBois, R.N. Meloxicam inhibits the growth of colorectal cancer cells. Carcinogenesis 1998, 19, 2195-2199. [CrossRef] [PubMed]

24. Ayakawa, S.; Shibamoto, Y.; Sugie, C.; Ito, M.; Ogino, H.; Tomita, N.; Kumagai, M.; Murakami, H.; Sawa, H. Antitumor effects of a cyclooxygenase-2 inhibitor, meloxicam, alone and in combination with radiation and/or 5-fluorouracil in cultured tumor cells. Mol. Med. Rep. 2009, 2, 621-625. [CrossRef] [PubMed]

25. Hanif, R.; Pittas, A.; Feng, Y.; Koutsos, M.I.; Qiao, L.; Staiano-Coico, L.; Shiff, S.I.; Rigas, B. Effects of nonsteroidal anti-inflammatory drugs on proliferation and on induction of apoptosis in colon cancer cells by a prostaglandin-independent pathway. Biochem. Pharmacol. 1996, 52, 237-245. [CrossRef]

26. Saini, M.K.; Sanya, S.N. Targeting angiogenic pathway for chemoprevention of experimental colon cancer using C-phycocyanin as cyclooxygenase-2 inhibitor. Biochem. Cell Biol. 2014, 92, 206-218. [CrossRef]

27. Krall, J.A.; Reinhardt, F.; Mercury, O.A.; Pattabiraman, D.R.; Brooks, M.W.; Dougan, M.; Lambert, A.W.; Bierie, B.; Ploegh, H.L.; Dougan, S.K.; et al. The systemic response to surgery triggers the outgrowth of distant immune-controlled tumors in mouse models of dormancy. Sci. Transl. Med. 2018, 10, eaan3464. [CrossRef]

28. Szczęśniak-Sięga, B.M.; Mogilski, S.; Wiglusz, R.J.; Janczak, J.; Maniewska, J.; Malinka, W.; Filipek, B. Synthesis and pharmacological evaluation of novel arylpiperazine oxicams derivatives as potent analgesics without ulcerogenicity. Bioorg. Med. Chem. 2019, 27, 1619-1628. [CrossRef]

29. Dakubo, G.D.; Jakupciak, J.P.; Birch-Machin, M.A.; Parr, R.L. Clinical implications and utility of field cancerization. Cancer Cell Int. 2007, 7, 2. [CrossRef]

30. Patel, A.; Tripathi, G.; Gopalakrishnan, K.; Williams, N.; Arasaradnam, R.P. Field cancerisation in colorectal cancer: A new frontier or pastures past? World J. Gastroenterol. 2015, 21, 3763-3772. [CrossRef] [PubMed]

31. Yamazaki, R.; Kusunoki, N.; Matsuzaki, T.; Hashimoto, S.; Kawai, S. Selective cyclooxygenase-2 inhibitors show a deferential ability to inhibit proliferation and induce apoptosis of colon adenocarcinoma cells. FEBS Lett. 2002, 531, 278-284. [CrossRef]

32. Tsikas, D.; Gutzki, F.M.; Stichtenoth, D.O. Circulating and excretory nitrite and nitrate as indicators of nitric oxide synthesis in humans: Methods of analysis. Eur. J. Clin. Pharmacol. 2006, 62, 51-59. [CrossRef]

33. Brankovic, B.; Stanojevic, G.; Stojanovic, I.; Veljkovic, A.; Kocic, G.; Janosevic, P.; Nestorovic, M.; Petrovic, D.; Djindjic, B.; Pavlovic, D.; et al. Nitric oxide synthesis modulation-A possible diagnostic and therapeutic target in colorectal cancer. J. BUON 2017, 22, 162-169. [PubMed]

34. Manna, S.K.; Tanaka, N.; Krausz, K.W.; Haznadar, M.; Xue, X.; Matsubara, T.; Bowman, E.D.; Fearon, E.R.; Harris, C.C.; Shah, Y.M.; et al. Biomarkers of coordinate metabolic reprogramming in colorectal tumors in mice and humans. Gastroenterology 2014, 146, 1313-1324. [CrossRef] 
35. Salimian Rizi, B.; Achreja, A.; Nagrath, D. Nitric oxide: The forgotten child of tumor metabolism. Trends Cancer 2017, 3, 659-672. [CrossRef]

36. Radi, R. Oxygen radicals, nitric oxide, and peroxynitrite: Redox pathways in molecular medicine. Proc. Natl. Acad. Sci. USA 2018, 115, 5839-5848. [CrossRef]

37. Hulin, J.A.; Gubareva, E.A.; Jarzebska, N.; Rodionov, R.N.; Mangoni, A.A.; Tommasi, S. Inhibition of Dimethylarginine Dimethylaminohydrolase (DDAH) Enzymes as an Emerging Therapeutic Strategy to Target Angiogenesis and Vasculogenic Mimicry in Cancer. Front. Oncol. 2020, 9, 1455. [CrossRef]

38. Saini, M.K.; Vaish, V.; Sanyal, S.N. Role of cytokines and Jak3/Stat3 signaling in the 1,2-dimethylhydrazine dihydrochloride-induced rat model of colon carcinogenesis: Early target in the anticancer strategy. Eur. J. Cancer Prev. 2013, 22, 215-228. [CrossRef]

39. Li, H.; Zhou, Y.; Zhao, A.; Qiu, Y.; Xie, G.; Jiang, Q.; Zheng, X.; Zhong, W.; Sun, X.; Zhou, Z.; et al. Asymmetric dimethylarginine attenuates serum starvation-induced apoptosis via suppression of the Fas (APO-1/CD95)/JNK (SAPK) pathway. Cell Death Dis. 2013, 4, e830. [CrossRef]

40. Kostourou, V.; Robinson, S.P.; Cartwright, J.E.; Whitley, G.S. Dimethylarginine dimethylaminohydrolase I enhances tumour growth and angiogenesis. Br. J. Cancer 2002, 87, 673-680. [CrossRef]

41. Vanella, L.; Di Giacomo, C.; Acquaviva, R.; Santangelo, R.; Cardile, V.; Barbagallo, I.; Abraham, N.G.; Sorrenti, V. The DDAH/NOS pathway in human prostatic cancer cell lines: Antiangiogenic effect of L-NAME. Int. J. Oncol. 2011, 39, 1303-1310. [CrossRef] [PubMed]

42. Hulin, J.A.; Tommasi, S.; Elliot, D.; Hu, D.G.; Lewis, B.C.; Mangoni, A.A. MiR-193b regulates breast cancer cell migration and vasculogenic mimicry by targeting dimethylarginine dimethylaminohydrolase 1. Sci. Rep. 2017, 7, 1-15. [CrossRef] [PubMed]

43. Reddy, K.R.K.; Dasari, C.; Duscharla, D.; Supriya, B.; Ram, N.S.; Surekha, M.V.; Kumar, J.M.; Ummanni, R. Dimethylarginine dimethylaminohydrolase-1 (DDAH1) is frequently upregulated in prostate cancer, and its overexpression conveys tumor growth and angiogenesis by metabolizing asymmetric dimethylarginine (ADMA). Angiogenesis 2018, 21, 79-94. [CrossRef] [PubMed]

44. Shiozawa, T.; Iyama, S.; Toshima, S.; Sakata, A.; Usui, S.; Minami, Y.; Sato, Y.; Hizawa, N.; Noguchi, M. Dimethylarginine dimethylaminohydrolase 2 promotes tumor angiogenesis in lung adenocarcinoma. Virchows Arch. 2016, 468, 179-190. [CrossRef]

45. Smith, C.L.; Birdsey, G.M.; Anthony, S.; Arrigoni, F.I.; Leiper, J.M.; Vallance, P. Dimethylarginine dimethylaminohydrolase activity modulates ADMA levels, VEGF expression, and cell phenotype. Biochem. Biophys. Res. Commun. 2003, 308, 984-989. [CrossRef]

46. Wojciak-Stothard, B.; Torondel, B.; Tsang, L.Y.; Fleming, I.; Fisslthaler, B.; Leiper, J.M.; Vallance, P. The ADMA/DDAH pathway is a critical regulator of endothelial cell motility. J. Cell Sci. 2007, 120, 929-942. [CrossRef]

47. Liu, X.J.; Hong, Q.; Wang, Z.; Yu, Y.Y.; Zou, X.; Xu, L.H. MicroRNA21 promotes interstitial fibrosis via targeting DDAH1: A potential role in renal fibrosis. Mol. Cell. Biochem. 2016, 411, 181-189. [CrossRef]

48. Ye, J.; Xu, J.; Li, Y.; Huang, Q.; Huang, J.; Wang, J.; Zhong, W.; Lin, X.; Chen, W.; Lin, X. DDAH1 mediates gastric cancer cell invasion and metastasis via Wnt/b-catenin signaling pathway. Mol. Oncol. 2017, 11, 1208-1224. [CrossRef]

49. Neubauer, K.; Bednarz-Misa, I.; Diakowska, D.; Kapturkiewicz, B.; Gamian, A.; Krzystek-Korpacka, M. Nampt/PBEF/visfatin upregulation in colorectal tumors, mirrored in normal tissue and whole blood of colorectal cancer patients, is associated with metastasis, hypoxia, IL1 $\beta$, and anemia. BioMed Res. Int. 2015, 2015, 523930. [CrossRef]

50. Krzystek-Korpacka, M.; Gorska, S.; Diakowska, D.; Kapturkiewicz, B.; Podkowik, M.; Gamian, A.; Bednarz-Misa, I. Midkine is up-regulated in both cancerous and inflamed bowel, reflecting lymph node metastasis in colorectal cancer and clinical activity of ulcerative colitis. Cytokine 2017, 89, 68-75. [CrossRef]

51. Bednarz-Misa, I.; Diakowska, D.; Krzystek-Korpacka, M. Local and systemic IL-7 concentration in gastrointestinal-tract cancers. Medicina 2019, 55, 262. [CrossRef]

52. Yang, Y.; Bedford, M.T. Protein arginine methyltransferases and cancer. Nat. Rev. Cancer 2013, 13, 37-50. [CrossRef]

53. Wei, H.H.; Fan, X.J.; Hu, Y.; Guo, M.; Fang, Z.Y.; Wu, P.; Tian, X.X.; Gao, S.X.; Peng, C.; Yang, Y.; et al. A systematic survey of PRMT interactomes reveals the key roles of arginine methylation in the global control of RNA splicing and translation. bioRxiv 2019, 746529. [CrossRef] 
54. Li, X.; Wang, C.; Jiang, H.; Luo, C. A patent review of arginine methyltransferase inhibitors (2010-2018). Expert Opin. Ther. Pat. 2019, 29, 97-114. [CrossRef]

55. Baldwin, R.M.; Morettin, A.; Côté, J. Role of PRMTs in cancer: Could minor isoforms be leaving a mark? World J. Biol. Chem. 2014, 5, 115-129. [CrossRef]

56. Mathioudaki, K.; Papadokostopoulou, A.; Scorilas, A.; Xynopoulos, D.; Agnanti, N.; Talieri, M. The PRMT1 gene expression pattern in colon cancer. Br. J. Cancer 2008, 99, 2094-2099. [CrossRef]

57. Lattouf, H.; Poulard, C.; Le Romancer, M. PRMT5 prognostic value in cancer. Oncotarget 2019, 10, 3151-3153. [CrossRef]

58. Ichikawa, T.; Shanab, O.; Nakahata, S.; Shimosaki, S.; Manachai, N.; Ono, M.; Iha, H.; Shimoda, K.; Morishita, K. Novel PRMT5-mediated arginine methylations of HSP90A are essential for maintenance of HSP90A function in NDRG2low ATL and various cancer cells. Biochim. Biophys. Acta Mol. Cell Res. 2020, 1867, 118615. [CrossRef]

59. Thun, M.J.; Henley, S.J.; Patrono, C. Nonsteroidal Anti-inflammatory Drugs as Anticancer Agents: Mechanistic, Pharmacologic, and Clinical Issues. J. Nat. Cancer Inst. 2002, 94, 252-266. [CrossRef]

60. Tao, L.; Kramer, P.M.; Wang, W.; Yang, S.; Lubet, R.A.; Steele, V.E.; Pereira, M.A. Altered expression of c-myc, p16 and p27 in rat colon tumors and its reversal by short-term treatment with chemopreventive agents. Carcinogenesis 2002, 23, 1447-1454. [CrossRef]

61. Carbone, P.P.; Douglas, J.A.; Larson, P.O.; Verma, A.K.; Blair, I.A.; Pomplun, M.; Tutsch, K.D. Phase I chemoprevention study of piroxicam and alphadifluoromethylornithine. Cancer Epidemiol. Biomark. Prev. 1998, 7, 907-912.

62. Calaluce, R.; Earnest, D.L.; Heddens, D.; Einspahr, J.G.; Roe, D.; Bogert, C.L.; Marshall, J.R.; Alberts, D.S. Effects of piroxicam on prostaglandin E2 levels in rectal mucosa of adenomatous polyp patients: A randomized phase IIb trial. Cancer Epidemiol. Biomark. Prev. 2000, 9, 1287-1292.

63. Finley, P.R.; Bogert, C.L.; Alberts, D.S.; Einspahr, J.; Earnest, D.L.; Blackwell, G.; Girodias, K. Measurement of prostaglandin E2 in rectal mucosa in human subjects: A method study. Cancer Epidemiol. Biomark. Prev. 1995, 4, 239-244.

64. Hatnapure, G.D.; Keche, A.P.; Rodge, A.H.; Birajdar, S.S.; Tale, R.H.; Kamble, V.M. Synthesis and biological evaluation of novel piperazine derivatives of flavone as potent anti-inflammatory and antimicrobial agent. Bioorg. Med. Chem. Lett. 2012, 22, 6385-6390. [CrossRef]

65. Malinka, W.; Kaczmarz, M.; Filipek, B.; Sapa, J.; Glod, B. Preparation of novel derivatives of pyridothiazine-1,1-dioxide and their CNS and antioxidant properties. Farmaco 2002, 57, 737-746. [CrossRef]

66. Dogruer, D.; Kupeli, E.; Yesilada, E.; Sahin, M.F. Synthesis of New 2-[1(2H)-Phthalazinon-2-yl]-acetamide and 3-[1(2H)-Phthalazinon-2-yl]-propanamide Derivatives as Antinociceptive and Anti-inflammatory Agents. Arch. Pharm. Med. Chem. 2004, 337, 303-310. [CrossRef]

67. Kus, K.; Kij, A.; Zakrzewska, A.; Jasztal, A.; Stojak, M.; Walczak, M.; Chlopicki, S. Alterations in arginine and energy metabolism, structural and signalling lipids in metastatic breast cancer in mice detected in plasma by targeted metabolomics and lipidomics. Breast Cancer Res. 2018, 20,1-13. [CrossRef]

68. Wu, Y.; He, C.; Hu, S.; Hu, Z.; Li, Y.; Xing, X.; Du, X. Downregulation of ARG2 inhibits growth of colorectal cancer cells and increases expression of the CD3乙 chain in co-cultured T-cells. Int. J. Clin. Exp. Med. 2019, 12, 6946-6957.

69. Pedrosa, L.; Esposito, F.; Thomson, T.M.; Maurel, J. The Tumor Microenvironment in Colorectal Cancer Therapy. Cancers 2019, 11, 1172. [CrossRef]

70. Miret, J.J.; Kirschmeier, P.; Koyama, S.; Zhu, M.; Li, Y.Y.; Naito, Y.; Wu, M.; Malladi, V.S.; Huang, W.; Walker, W.; et al. Suppression of Myeloid Cell Arginase Activity leads to Therapeutic Response in a NSCLC Mouse Model by Activating Anti-Tumor Immunity. J. Immunother. Cancer 2019, 7, 32. [CrossRef]

71. Morris, S.M. Arginine metabolism: Boundaries of our knowledge. J. Nutr. 2007, 137, 1602S-1609S. [CrossRef] [PubMed]

72. Porembska, Z.; Zabek, J.; Grabon, W.; Rahden-Staroń, I.; Barańczyk-Kuźma, A. Arginase isoforms in human colorectal cancer. Clin. Chim. Acta 2001, 305, 157-165. [CrossRef] 
73. Mielczarek-Puta, M.; Graboń, W.; Chrzanowska, A.; Barańczyk-Kuźma, A. Arginase and arginine in diagnostics of patients with colorectal cancer and patients with colorectal cancer liver metastases. Contemp. Oncol. Wspolczesna Onkol. 2008, 12, 51-55.

74. Ma, Z.; Lian, J.; Yang, M.; Wuyang, J.; Zhao, C.; Chen, W.; Liu, C.; Zhao, Q.; Lou, C.; Han, J.; et al. Overexpression of Arginase-1 is an indicator of poor prognosis in patients with colorectal cancer. Pathol. Res. Pract. 2019, 215, 152383. [CrossRef]

75. Czystowska-Kuzmicz, M.; Sosnowska, A.; Nowis, D.; Ramji, K.; Szajnik, M.; Chlebowska-Tuz, J.; Wolinska, E.; Gaj, P.; Grazul, M.; Pilch, Z.; et al. Small extracellular vesicles containing arginase-1 suppress T-cell responses and promote tumor growth in ovarian carcinoma. Nat. Commun. 2019, 10, 3000. [CrossRef]

76. Ma, Z.; Zhen, Y.; Hu, C.; Yi, H. Myeloid-Derived Suppressor Cell-Derived Arginase-1 Oppositely Modulates IL-17A and IL-17F through the ESR/STAT3 Pathway during Colitis in Mice. Front. Immunol. 2020, 11, 687. [CrossRef]

77. Mayorek, N.; Naftali-Shani, N.; Grunewald, M. Diclofenac Inhibits Tumor Growth in a Murine Model of Pancreatic Cancer by Modulation of VEGF Levels and Arginase Activity. PLoS ONE 2010, 5, e12715. [CrossRef]

78. Verma, A.K.; Ashendel, C.L.; Boutwell, R.K. Inhibition by prostaglandin synthesis inhibitors of the induction of epidermal ornithine decarboxylase activity, the accumulation of prostaglandins, and tumor promotion caused by 12-O-tetradecanoylphorbol-13-acetate. Cancer Res. 1980, 40, 308-315.

79. Closs, E.I.; Simon, A.; Vekony, N.; Rotmann, A. Plasma membrane transporters for arginine. J. Nutr. 2004, 134, 2752S-2759S. [CrossRef]

80. Krzyżak, E.; Szczęśniak-Sięga, B.; Malinka, W. Synthesis and thermal behaviour of new benzo-1,2-thiazine long-chain aryl-piperazine derivatives. J. Therm. Anal. Calorim. 2014, 115, 793-802. [CrossRef]

81. Szczęśniak-Sięga, B.; Maniewska, J.; Poła, A.; Środa-Pomianek, K.; Malinka, W.; Michalak, K. Synthesis of new Piroxicam analogues and their influence on lipid bilayers. Acta Pol. Pharm. Drug Res. 2014, 71, 1045-1050. [CrossRef]

82. Maniewska, J.; Szczęśniak-Sięga, B.; Poła, A.; Środa-Pomianek, K.; Malinka, W.; Michalak, K. The interaction of new piroxicam analogues with lipid bilayers-a calorimetric and fluorescence spectroscopic study. Acta Pol. Pharm. Drug Res. 2014, 71, 1004-1012. [CrossRef]

83. Krzystek-Korpacka, M.; Diakowska, D.; Bania, J.; Gamian, A. Expression stability of common housekeeping genes is differently affected by bowel inflammation and cancer: Implications for finding suitable normalizers for inflammatory bowel disease studies. Inflamm. Bowel Dis. 2014, 20, 1147-1156. [CrossRef]

84. Vandesompele, J.; De Preter, K.; Pattyn, F.; Poppe, B.; Van Roy, N.; De Paepe, A.; Speleman, F. Accurate normalization of real-time quantitative RT-PCR data by geometric averaging of multiple internal control genes. Genome Biol. 2002, 3, Research0034. [CrossRef]

85. Fleszar, M.G.; Wiśniewski, J.; Krzystek-Korpacka, M.; Misiak, B.; Frydecka, D.; Piechowicz, J.; Lorenc-Kukuła, K.; Gamian, A. Quantitative analysis of L-arginine, dimethylated arginine derivatives, L-citrulline, and dimethylamine in human serum using liquid chromatography-mass spectrometric method. Chromatographia 2018, 81, 911-921. [CrossRef]

86. Chachaj, A.; Wiśniewski, J.; Rybka, J.; Butrym, A.; Biedroń, M.; Krzystek-Korpacka, M.; Fleszar, M.G.; Karczewski, M.; Wróbel, T.; Mazur, G.; et al. Asymmetric and symmetric dimethylarginines and mortality in patients with hematological malignancies-A prospective study. PLoS ONE 2018, 13, e0197148. [CrossRef] [PubMed]

87. Krzystek-Korpacka, M.; Wiśniewski, J.; Fleszar, M.G.; Bednarz-Misa, I.; Bronowicka-Szydełko, A.; Gacka, M.; Masłowski, L.; Kędzior, K.; Witkiewicz, W.; Gamian, A. Metabolites of the nitric oxide (NO) pathway are altered and indicative of reduced $\mathrm{NO}$ and arginine bioavailability in patients with cardiometabolic diseases complicated with chronic wounds of lower extremities: Targeted metabolomics approach (LC-MS/MS). Oxid. Med. Cell. Longev. 2019, 2019, 5965721. [CrossRef] [PubMed]

88. Fleszar, M.G.; Wiśniewski, J.; Zboch, M.; Diakowska, D.; Gamian, A.; Krzystek-Korpacka, M. Targeted metabolomic analysis of nitric oxide/L-arginine pathway metabolites in dementia: Association with pathology, severity, and structural brain changes. Sci. Rep. 2019, 9, 13764. [CrossRef] 
89. Smith, P.K.; Krohn, R.I.; Hermanson, G.T.; Mallia, A.K.; Gartner, F.H.; Provenzano, M.D.; Fujimoto, E.K.; Goeke, N.M.; Olson, B.J.; Klenk, D.C. Measurement of protein using bicinchoninic acid. Anal. Biochem. 1985, 150, 76-85. [CrossRef]

90. Laemmli, U.K. Cleavage of structural proteins during the assembly of the head of bacteriophage T4. Nature 1970, 227, 680-685. [CrossRef]

(C) 2020 by the authors. Licensee MDPI, Basel, Switzerland. This article is an open access article distributed under the terms and conditions of the Creative Commons Attribution (CC BY) license (http://creativecommons.org/licenses/by/4.0/). 